\title{
Retrieval of temperature and pressure using broadband solar occultation: SOFIE approach and results
}

\author{
B. T. Marshall ${ }^{1}$, L. E. Deaver ${ }^{1}$, R. E. Thompson ${ }^{1}$, L. L. Gordley ${ }^{1}$, M. J. McHugh ${ }^{1}$, M. E. Hervig ${ }^{2}$, and J. M. Russell III ${ }^{3}$ \\ ${ }^{1}$ GATS, Inc., 11864 Canon Blvd., Suite 101, Newport News, VA, 23606, USA \\ ${ }^{2}$ GATS, Inc., 65 South Main St., Suite 5, Driggs, ID, 83422, USA \\ ${ }^{3}$ Center for Atmospheric Sciences at Hampton University, 23 Tyler St., Hampton, VA, 23668, USA
}

Received: 3 November 2010 - Published in Atmos. Meas. Tech. Discuss.: 17 December 2010

Revised: 30 March 2011 - Accepted: 6 May 2011 - Published: 18 May 2011

\begin{abstract}
Measurement of atmospheric temperature as a function of pressure, $T(P)$, is key to understanding many atmospheric processes and a prerequisite for retrieving gas mixing ratios and other parameters from solar occultation measurements. This paper gives a brief overview of the solar occultation measurement technique followed by a detailed discussion of the mechanisms that make the measurement sensitive to temperature. Methods for retrieving $T(P)$ using both broadband transmittance and refraction are discussed. Investigations using measurements of broadband transmittance in two $\mathrm{CO}_{2}$ absorption bands (the 4.3 and $2.7 \mu \mathrm{m}$ bands) and refractive bending are then presented. These investigations include sensitivity studies, simulated retrieval studies, and examples from SOFIE.
\end{abstract}

\section{Introduction}

Broadband solar occultation has been used for decades to remotely measure atmospheric constituents. Using the solar image as a source along with precise pointing knowledge permits a reliable, consistent, and accurate long-term measurement of important species. For example, the Stratospheric Aerosol and Gas Experiment II (SAGE-II) (McCormick et al., 1989), monitored density, ozone, water, and aerosol for over $21 \mathrm{yr}$, and the Halogen Occultation Experiment (HALOE) (Russell et al., 1993), monitored these along with several halogen species and temperature as a function of pressure, $T(P)$, for over $14 \mathrm{yr}$. More recently, the Solar Occultation For Ice Experiment (SOFIE) (Gordley et al., 2009b), has achieved remarkable measurements of polar

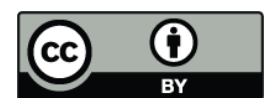

Correspondence to: B. T. Marshall (b.t.marshall@gats-inc.com) mesospheric clouds, mesospheric trace gases and $T(P)$. Accurate constituent retrievals depend strongly upon measurement fidelity and high quality coincident $T(P)$ profiles. The three experiments mentioned above use broadband atmospheric transmittance measurements and have all depended, to some degree, on auxiliary sources of $T(P)$ and gas mixing ratios. Specifically, the analysis used on HALOE (Hervig et al., 1996), and the first two public data versions of SOFIE use $\mathrm{CO}_{2}$ transmittance to retrieve $T(P)$ above $35 \mathrm{~km}$, but depend on NCEP data (Wu et al., 2002), at lower altitudes and on an assumed $\mathrm{CO}_{2}$ concentration profile at all altitudes. Solar occultation measurements of atmospheric refractive bending can also be used to infer $T(P)$, (Ward and Herman, 1998). The latest version (1.03) of SOFIE data uses such measurements to retrieve $T(P)$ below $\sim 60 \mathrm{~km}$ (Gordley et al., 2009a).

\section{Solar occultation measurement overview}

A schematic of a solar occultation measurement is shown in Fig. 1. The Sun as viewed from a satellite appears to rise and set once per orbit. Since the solar radiation is far greater than the atmospheric thermal emission, the atmospheric effect on the signal above the tropopause comes almost entirely from atmosphere absorption and scattering (extinction) of the solar radiation. When considering only single scattering (multiple scattering, which is important in the troposphere is not considered in this study) and absorption, the atmospheric radiative transfer (RT) problem is greatly simplified. For this situation the broadband radiance, $L_{S}$, observed by an instrument along the path $S$ can be described as:

$L_{S}=C \int F(v) J(v) \tau_{S}(v) d v$

Published by Copernicus Publications on behalf of the European Geosciences Union. 


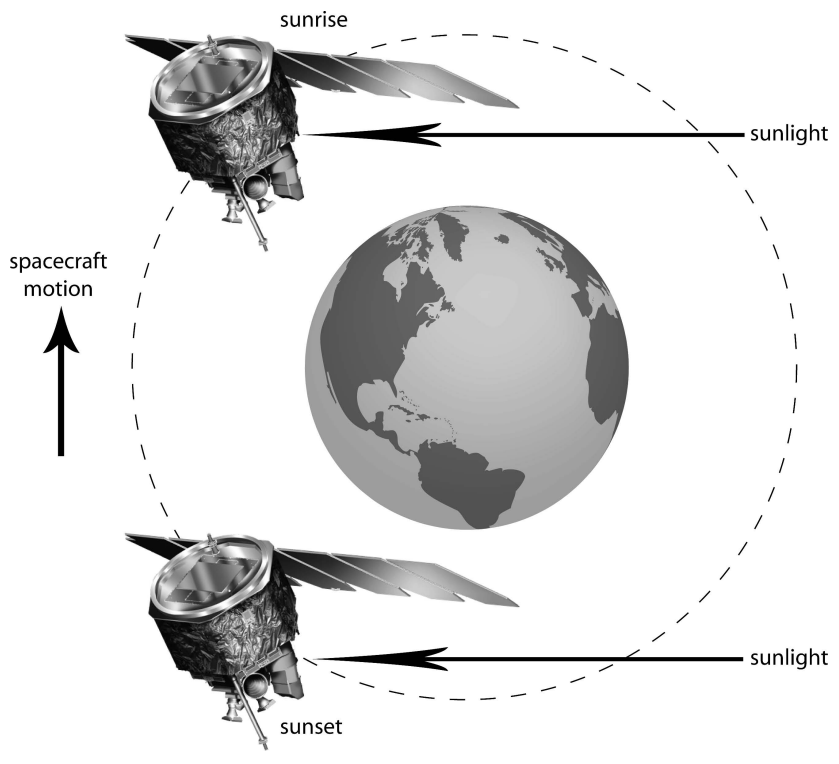

Fig. 1. Solar occultation geometry.

where $C$ is a signal gain (response) constant, $F$ is the instrument spectral response, $J$ is the solar source function, $\tau_{S}$ is the transmittance of the path $S$, and $v$ is wavenumber. For limb-paths above the atmosphere, Eq. (1) reduces to $L_{\text {exo }}$ :

$L_{\text {exo }}=C \int F(v) J(v) d v$.

The instrument and solar source function weighted mean transmittance along the path $S$ can then be defined as:

$\bar{\tau}_{S}=L_{S} / L_{\text {exo }}$.

Use of this ratio formulation simplifies the signal model and retrieval algorithm.

Non-local thermodynamic equilibrium (nLTE) effects are minimized by measuring spectral bands where the atmospheric extinction is dominated by ground state transitions. However, for some of the SOFIE channels it is necessary to account for nLTE processes in the lower thermosphere and in the vicinity of the very cold polar summer mesopause region, where hot-bands contribute significantly to total band extinction (Gordley et al., 2009b). This is discussed in more detail in Sect. 6.

Retrieval of $T(P)$ from broadband limb-path transmittance measurements requires both a detailed RT model and knowledge of the atmospheric constituents that contribute to absorption and scatter of radiation along the observed path. These requirements are eliminated when using refraction measurements because retrievals based on refraction measurements depend only on the physics of hydrostatic balance and the relationship of refractivity to density. Limitations in using this technique with solar imaging are primarily due to errors introduced by pointing knowledge uncertainty and errors in upper boundary assumptions, as will be described in Sect. 6.
Whether measurements are from solar occultation or thermal emission, retrieval of $T(P)$ requires precise knowledge of the pointing angle between samples. However, since solar occultation techniques rely on the retrieval of neutral density profiles for determining pressure and temperature through the integration of the hydrostatic equation, spacecraft pointing requirements are even more challenging. The density profiles may be inferred either from transmittance measurements or refraction angle measurements that can be obtained by tracking the solar disk (Gordley et al., 2009a,b).

\section{Sensitivity analysis for broadband transmittance measurements}

Retrieving temperature from broadband limb transmittance measurements requires careful attention to the physical mechanisms that produce the temperature dependence. In developing the algorithms used on HALOE and SOFIE, we investigated the major mechanisms that produce sensitivity to the temperature profile. The simulations presented in this paper use the LINEPAK (Gordley et al., 1994), and BANDPAK (Marshall et al., 1994), RT models, which have been used for over $20 \mathrm{yr}$ in many remote sensing missions. LINEPAK is the core RT model used in the online SpectralCalc tool (http://www.spectralcalc.com/info/about.php). The HITRAN 2000 (Rothman et al., 2003) database is used for spectroscopic data. Note that the following simulations include all isotopes contained in the HITRAN database and implicitly assume the isotopic abundances used therein. The $\mathrm{CO}_{2}$ bands used in the following analyses are from SOFIE. Specifically, the $4.3 \mu \mathrm{m}$ band is modeled using the bandpass $2259-2370 \mathrm{~cm}^{-1}$ and the $2.7 \mu \mathrm{m}$ band is modeled using the bandpass $3555-3626 \mathrm{~cm}^{-1}$ (though we refer to the later band as $2.7 \mu \mathrm{m}$, it is centered at $2.78 \mu \mathrm{m}$ ). Also, note that HALOE has only a single $\mathrm{CO}_{2}$ channel in the $2.8 \mu \mathrm{m}$ region (3540$3600 \mathrm{~cm}^{-1}$ ), similar to the SOFIE band used in the following analyses.

We begin by looking at the sensitivity of broadband extinction to atmospheric temperature changes. Simulated limb extinction profiles for two $\mathrm{CO}_{2}$ bands (the SOFIE 4.3 and $2.7 \mu \mathrm{m}$ bands) as observed through the US Standard Atmosphere are shown in Fig. 2, which also displays a typical extinction profile for the $760 \mathrm{~nm} \mathrm{O}_{2}$ A-band (12970$13170 \mathrm{~cm}^{-1}$ ). Though we do not show retrieval examples for this band, we include it here to illustrate band selection considerations.

The primary physical mechanisms that cause limb-path transmittance measurements to be sensitive to atmospheric temperature are:

1. The effective band extinction, $B$, including the effects of temperature dependences of line intensities and half widths, with transition from Doppler-broadened at high altitudes to pressure-broadened at low altitudes. 


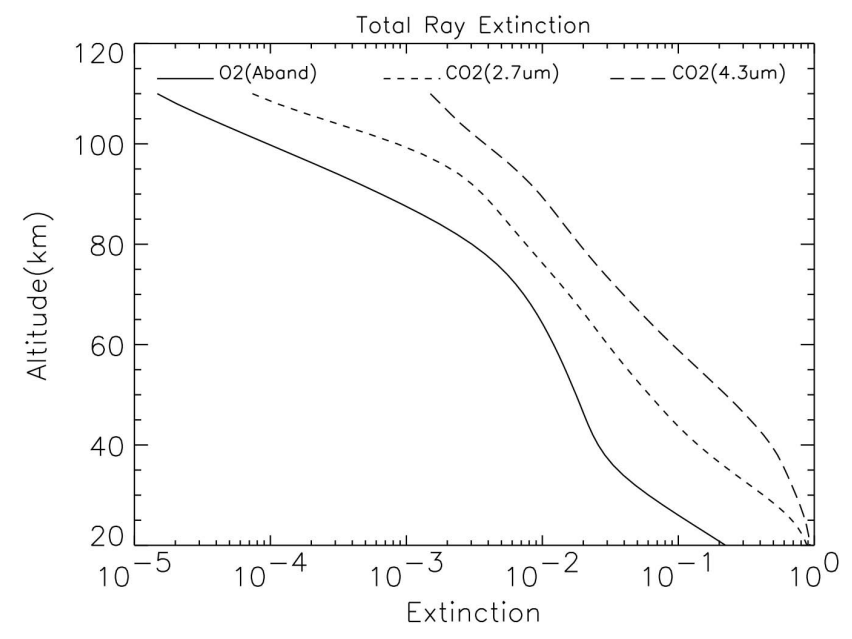

Fig. 2. Broadband limb-path extinction profiles for the $760 \mathrm{~nm}$ $\mathrm{O}_{2}$ A-band and 2.7 and $4.3 \mu \mathrm{m} \mathrm{CO}_{2}$. Extinction is defined as $\left(1-\bar{\tau}_{S}\right)$.

2. The ideal gas law, $I$, stating that density is inversely proportional to temperature.

3. Atmospheric hydrostatic equilibrium, $H$, that couples pressure to temperature via the differential formula

$d P(z)=-P(z) g(z) d z / R_{\mathrm{air}} T(z)$,

where $P$ is pressure, $z$ is altitude, $g$ is gravitational acceleration, $T$ is temperature and $R_{\text {air }}=R^{*} / M_{\text {air }}$, where $R^{*}$ is the universal gas constant and $M_{\text {air }}$ is the average molecular weight of the air.

Note that given a temperature profile and a defined pressure at one altitude, the pressures at all other altitudes can be determined by integrating Eq. (4). Similarly, given a pressure profile and defined temperature at one altitude, the temperature at all other altitudes can be calculated. Maintaining the hydrostatic boundary condition adds complications to limb temperature retrievals, but provides an essential physical constraint. A change in temperature at any altitude will change pressure at altitudes above or below depending on the direction of integration. The Earth's atmosphere is in hydrostatic equilibrium well into the lower thermosphere, but $R_{\text {air }}$ begins to vary at altitudes where diffusive effects become important and $M_{\text {air }}$ changes. The work in this paper assumes that $R_{\text {air }}$ is constant.

Figures 3-6 show the sensitivity results for the 4.3 and $2.7 \mu \mathrm{m} \mathrm{CO} \mathrm{CO}_{2}$ bands and the $760 \mathrm{~nm} \mathrm{O} \mathrm{O}_{2}$ A-band for a set of tangent altitudes with a vertical spacing $(\Delta z)$ of $2 \mathrm{~km}$. A $2 \mathrm{~km}$ altitude spacing was found to be a good compromise between retrieval stability and vertical resolution. The curves labeled $B, I$ and $H$ show the sensitivity of limb-path extinction to a $1 \mathrm{~K}$ temperature change at the tangent altitude due only to each of the physical mechanisms discussed

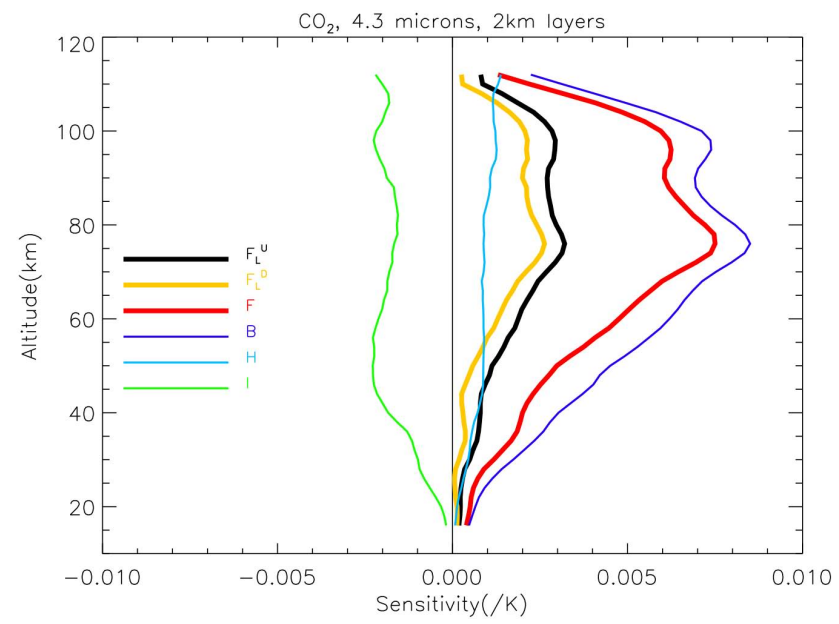

Fig. 3. $F_{\mathrm{L}}{ }^{\mathrm{U}}-$ Sensitivity of $4.3 \mu \mathrm{m} \mathrm{CO} 2$ limb path extinction to $1 \mathrm{~K}$ change at the tangent altitude, keeping layers below fixed. $F_{\mathrm{L}}{ }^{\mathrm{D}}-$ Sensitivity to $1 \mathrm{~K}$ change at the tangent point, keeping layers above fixed. $F$ - Sensitivity to $1 \mathrm{~K}$ change in all layers at or above the tangent altitude, keeping layers below fixed. $B$-Sensitivity due to temperature used for line strength and broadening. $H$ - Sensitivity due to impact on hydrostatic pressure (hydrostatic equilibrium maintained at all altitudes). $I$ - Sensitivity due to impact of the ideal gas law. Sensitivity is defined as the fractional change of broadband extinction through a perturbed atmosphere relative to unperturbed. In the case of $F$, the perturbation is a $1 \mathrm{~K}$ change to all layers from the tangent point upwards. For all others, the perturbation is a $1 \mathrm{~K}$ change to the tangent layer alone.

above. These three curves demonstrate the competing physical mechanisms that affect the measured signals. The curves labeled $F_{\mathrm{L}}^{\mathrm{U}}$ show the total fractional change in limb-path extinction due to a $1 \mathrm{~K}$ perturbation at the tangent point, with pressures adjusted from the tangent point upwards to restore hydrostatic balance. This curve represents the total sensitivity seen by a simple reverse onion peel procedure. The reverse onion peel iterates a bottom-up retrieval until all altitudes have converged to a stable temperature-pressure profile. The $F_{\mathrm{L}}{ }^{\mathrm{D}}$ curves show the sensitivity for the case where the pressures are adjusted only at the tangent level. These curves represent a traditional onion peel approach where the atmosphere is fixed above the tangent level, and thus only requires a single top-down iteration. While developing the retrieval codes used for HALOE and SOFIE, we explored a number of more complicated retrieval schemes and finally settled on the procedure depicted by the curves labeled $F$, which are similar to $F_{\mathrm{L}} \mathrm{U}$ except in this case the temperatures are perturbed for the tangent point and all points above. This procedure is similar to the bottom-up procedure described by Mill and Drayson (1978). Like the simple reverse onion peel procedure, this procedure requires iteration until all levels have converged.

Figures 3 and 4 show the sensitivities for the 4.3 and $2.7 \mu \mathrm{m}$ bands of $\mathrm{CO}_{2}$, and Figs. 5 and 6 for two different 


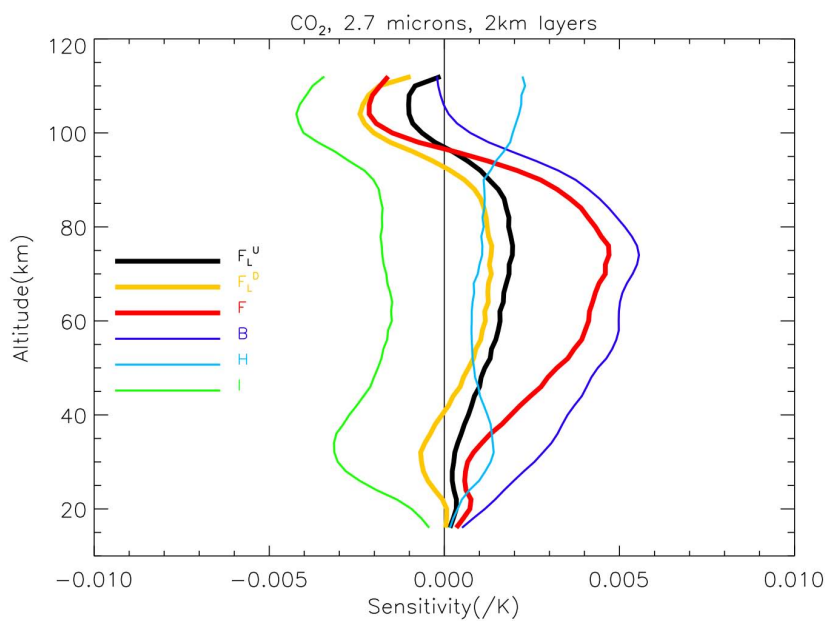

Fig. 4. Same as Fig. 3 but for the $2.7 \mu \mathrm{m} \mathrm{CO}_{2}$ band.

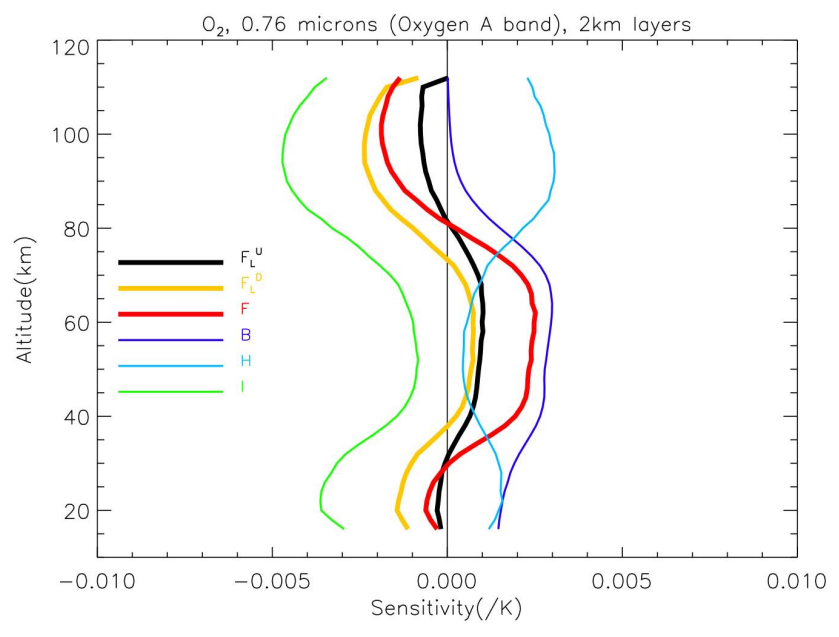

Fig. 5. Same as Fig. 3 but for $\mathrm{O}_{2}$ A-band.

parts of the $\mathrm{O}_{2}$ A-band. The sensitivity curves for $F$ are mostly positive in the stratosphere and mesosphere. Altitude regions where these curves are close to zero contain little information that can be used to infer temperature. The $4.3 \mu \mathrm{m}$ band of $\mathrm{CO}_{2}$ has a broader range of usable sensitivities for $F$ than the $2.7 \mu \mathrm{m}$ band. Also, as can be seen in Fig. 5, the $\mathrm{O}_{2}$ A-band has little temperature sensitivity for $F$ near $30 \mathrm{~km}$ and near $80 \mathrm{~km}$. However, additional investigations into the temperature sensitivity of various sub-bands led to the determination that the long-wave side of the A-band P-branch (12985-13065 $\mathrm{cm}^{-1}$ ) provides very high sensitivity (Fig. 6). This is because of the much larger temperature dependence of line strength for this part of the band and exemplifies the importance of band selection.

These results demonstrate that, for all cases investigated, the scheme used by HALOE and SOFIE, $F$, to retrieve $T(P)$ from broadband transmission measurements has good sensitivity over a larger altitude range than the other two schemes.

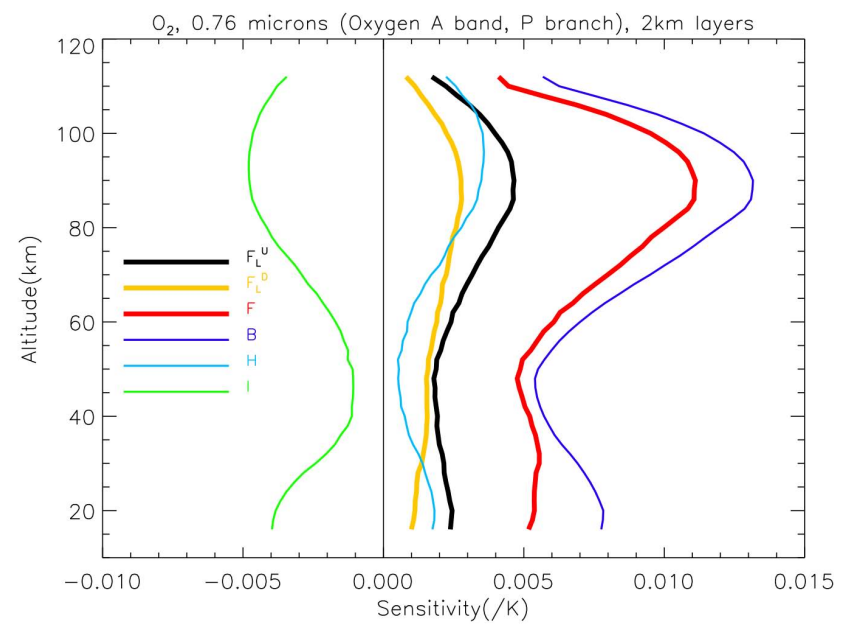

Fig. 6. Same as Fig. 5 but using only the weaker part of the P-branch of the $\mathrm{O}_{2}$ A-band.

It also illustrates the relative sensitivity of each band, and demonstrates the importance of band selection. The $4.3 \mu \mathrm{m}$ $\mathrm{CO}_{2}$ band offers obvious advantages particularly in the upper mesosphere and lower thermosphere as does the partial P-branch of the $\mathrm{O}_{2}$ A-band. We are not aware of any satellite remote sensing projects that have successfully used broadband measurements in the vicinity of the $\mathrm{O}_{2} \mathrm{~A}$-band for retrieval of $T(P)$. Our investigations suggest that, if using a single broadband, the best results are obtained by using only the weak long-wave portion of the P-branch, well away from the P-branch center.

Sensitivity analyses like those described above are a necessary first step in designing a measurement and retrieval system but do not necessarily provide a realistic assessment of retrieval capability. At altitudes where the sensitivity becomes too small, a retrieval algorithm will have no information from which to infer temperature and the retrieval will fail, unless constrained with a-priori data. Due to hydrostatic equilibrium, such failures are not limited to the region of low sensitivity but propagate in the direction of the hydrostatic integration. For onion peel algorithms, any failures can also propagate downward due to errors at upper altitudes impacting the forward model of limb-paths at lower tangent points. This is particularly true for the reverse algorithms (e.g. F) since several iterations are required for convergence, each iteration potentially propagates errors further from their point of origin. The HALOE and SOFIE retrieval algorithms are designed without explicit a-priori constraints, and we do not investigate their use in this work. Even so, for the $F$ algorithm described in this section, the retrieval is expected to work very well from the lowest altitude at which significant positive sensitivity is attained to at least the altitude of maximum sensitivity (peak altitude) and likely well beyond. To achieve a better understanding of the basic retrieval capability of the algorithm, detailed simulation studies are required. 


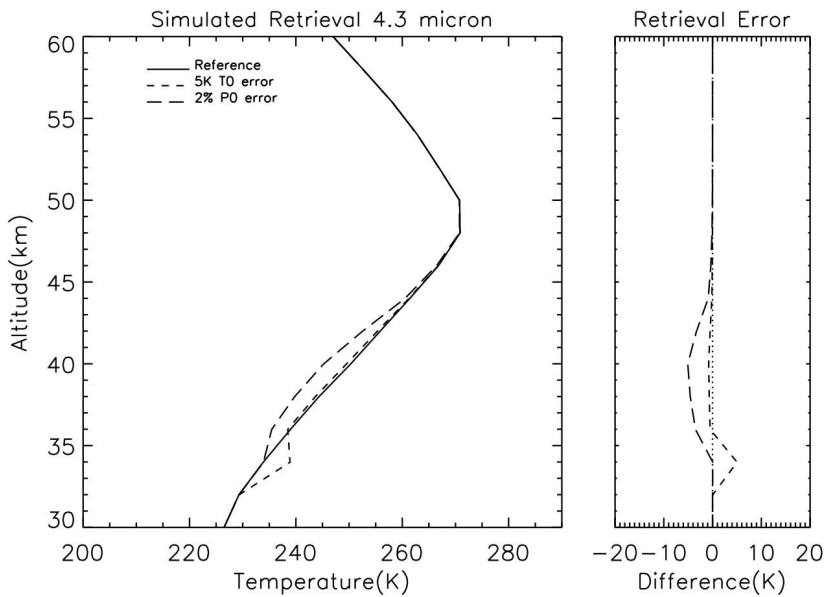

Fig. 7. Effect of lower boundary $(34 \mathrm{~km})$ temperature and pressure errors on temperature retrieved from $4.3 \mu \mathrm{m} \mathrm{CO}_{2}$. Solid lines are retrievals without boundary layer error, and dashed lines are retrievals with incorrect boundary layer conditions. Right-hand panel shows the errors.

The following section describes the basic numerical procedure used by HALOE and SOFIE for the limb-path transmittance measurements in the 4.3 and $2.7 \mu \mathrm{m} \mathrm{CO}_{2}$ bands and discusses the results of simulated retrievals used to investigate some of the major error mechanisms.

\section{Basic retrieval procedure and error mechanisms}

As discussed in the previous section, the algorithm used to retrieve temperature as a function of pressure, $T(P)$, from HALOE and SOFIE transmittance data is expected to work well from the lower stratosphere well into the mesosphere, and for the $4.3 \mu \mathrm{m}$ band used on SOFIE, potentially into the lower thermosphere. This section takes a closer look at the numerical procedure and investigates some of the major error mechanisms.

Using an appropriate NCEP profile as an initial guess and assuming a fixed $\mathrm{CO}_{2}$ concentration, the HALOE and SOFIE retrievals begin at some specified altitude, $z_{0}$, typically near $30 \mathrm{~km}$. Temperature, $T$, and pressure, $P$, at and below $z_{0}$ remain unaltered throughout the retrieval process. Above $z_{0}, T$ and $P$ are adjusted until the modeled transmittance profile matches the measured, while maintaining hydrostatic balance. Fixing the atmospheric conditions at $z_{0}$ provides a constraint to the retrieval process but also introduces an error source. Here we examine the effect of this error, along with effects of measurement noise and pointing jitter. Errors arising from spectroscopy, instrument model, and solar source function model are not investigated in this paper, but reliable retrievals depend on careful evaluation of these effects.

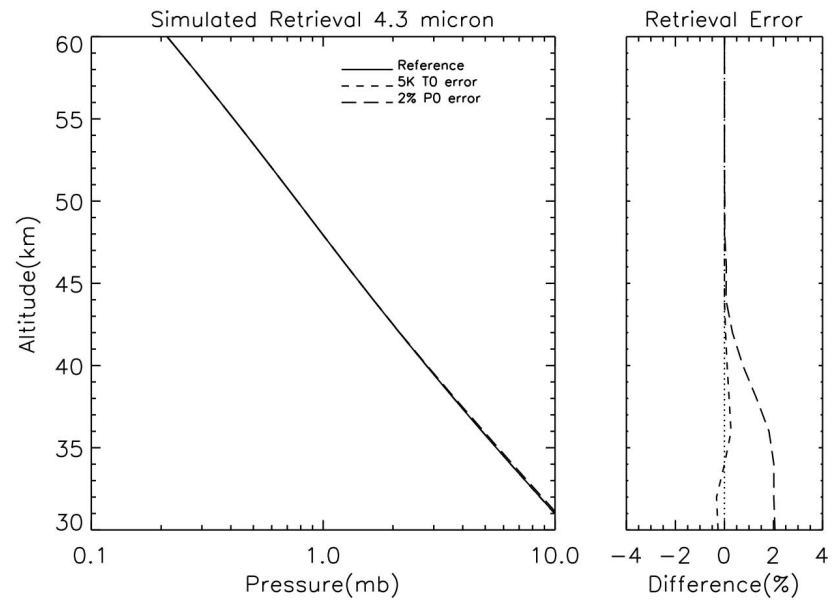

Fig. 8. Same as Fig. 7 but for pressure.

The analysis in the previous section suggests that the $4.3 \mu \mathrm{m} \mathrm{CO} 2$ band provides excellent information for temperature retrievals from the middle stratosphere well into the lower thermosphere. While the $2.7 \mu \mathrm{m}$ band does not perform quite as well, it still provides significant information into the upper mesosphere. Simulated retrievals are performed for the $\mathrm{CO}_{2}$ bands of interest to determine the expected performance. Simulated signal profiles $(\Delta z=2 \mathrm{~km})$ are constructed for each band using the LINEPAK and BANDPAK radiative transfer software to solve Eqs. (1-3). Random noise is applied to the transmittance profiles prior to performing the retrieval. These transmittance signals are then used to retrieve temperature and pressure with the algorithm described above, $F$. The retrievals start with an isothermal atmosphere ( $230 \mathrm{~K}$ for these examples) and iterate until convergence. We begin with low noise $\left(10^{-7}\right.$ random error on the limb-path transmittances) retrieval simulations for the standard atmosphere to assess the effect of incorrect lower boundary pressure and temperature. Figures $7-10$ show the results: the lines with long dashes correspond to a $2 \%$ pressure error at $z_{0}(34 \mathrm{~km}$ for these simulations) and the lines with short dashes show the impact of a $5 \mathrm{~K}$ temperature error at $z_{0}$. Note that though the lower boundary errors have significant impact, the retrieval returns to the correct profile within 10 to $15 \mathrm{~km}$. The $4.3 \mu \mathrm{m}$ band (Figs. 7 and 8 ) is much less sensitive to boundary layer errors than the $2.7 \mu \mathrm{m}$ band (Figs. 9 and 10), and both bands exhibit higher sensitivity to pressure error than to temperature error. Note that the pressure errors extend below $z_{0}$ for these (and subsequent) figures because $P(z)$ is recalculated using Eq. (4). The very different responses of the two bands to lower boundary pressure error suggests that we may be able to use that information in a two channel retrieval to independently retrieve lower boundary pressure. We investigate this possibility in Sect. 5 .

The impact of random measurement noise is demonstrated in Figs. 11-14, where simulations are shown for a limb-path 

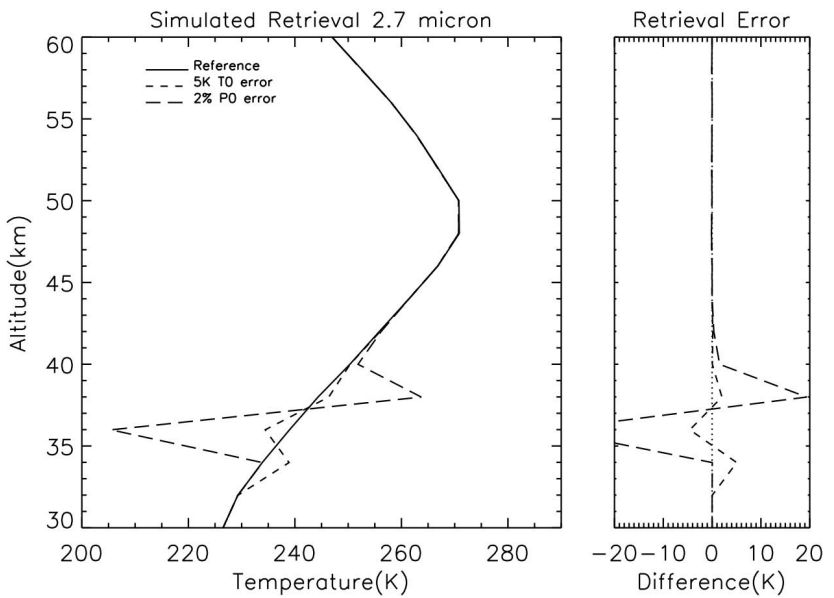

Fig. 9. Same as Fig. 7 but for the $2.7 \mu \mathrm{m} \mathrm{CO}_{2}$ band.
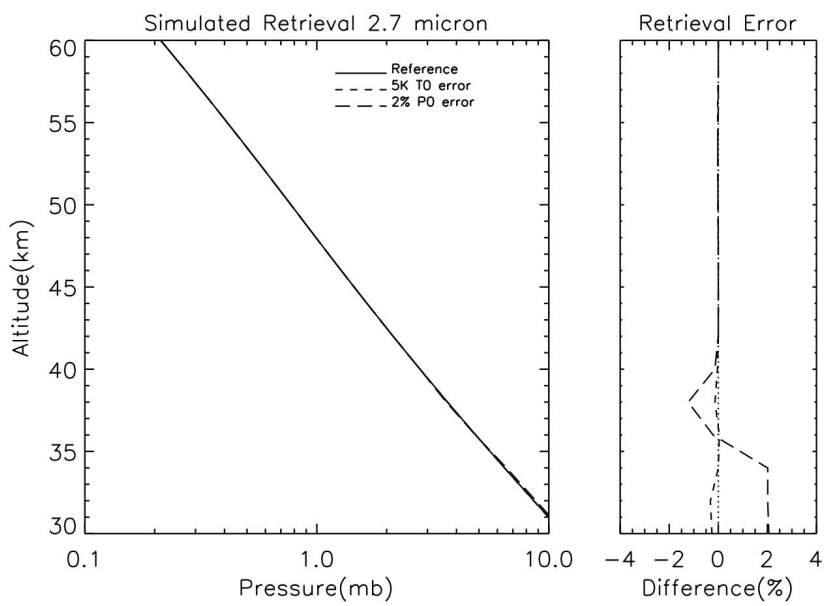

Fig. 10. Same as Fig. 9 but for pressure.

random transmittance error of $10^{-5}$. The dashed curve in the right hand panel for each plot shows the impact of random measurement noise while the solid curve shows the mean retrieval error. In general these simulations support the findings in Sect. 3. The $4.3 \mu \mathrm{m}$ band (Figs. 11 and 12) yields more robust temperature and pressure retrieval results and is more stable at both high and low altitudes than the $2.7 \mu \mathrm{m}$ band (Figs. 13 and 14). The pressure results for the 4.3 band (Fig. 12) are remarkable, primarily due to the strength of the 4.3 band. Comparing these results to the sensitivities shown in Figs. 3 and 4, it is apparent that the retrievals begin to fail where the sensitivity functions begin to fall off sharply above peak altitudes.

Another source of error is instrument pointing knowledge. This is modeled as a random noise on tangent point altitudes and is often referred to as jitter. The impact of pointing jitter on the $4.3 \mu \mathrm{m}$ band retrieval is demonstrated in Fig. 15, where retrievals are performed on simulated measurements with 1 and 5 arc sec jitter. For this simulation a profile with

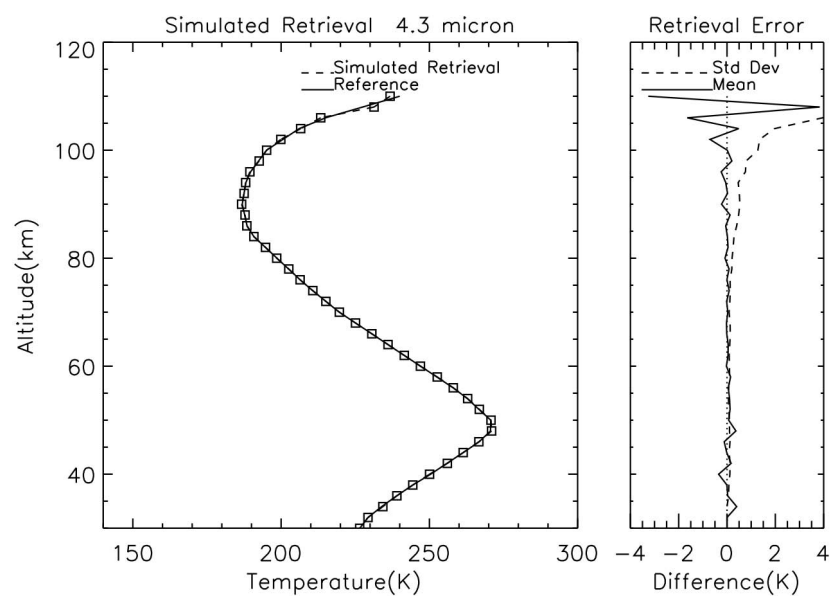

Fig. 11. Simulated temperature retrieval results for the $4.3 \mu \mathrm{m} \mathrm{CO}$ band. Right-hand panel shows the mean error and error standard deviation due to $10^{-5}$ random measurement error on broadband averaged transmittance.
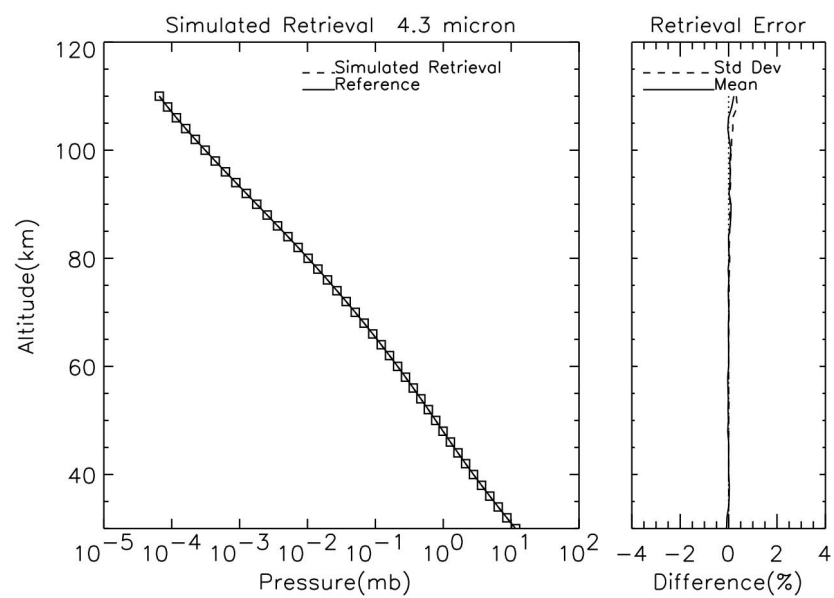

Fig. 12. Same as Fig. 11 but for pressure.
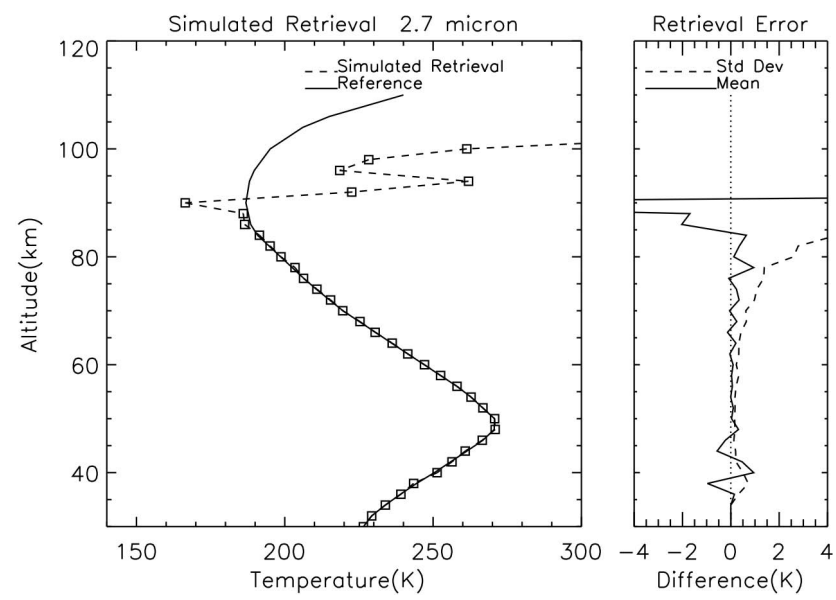

Fig. 13. Same as Fig. 11 but for the $2.7 \mu \mathrm{m} \mathrm{CO}_{2}$ band. 

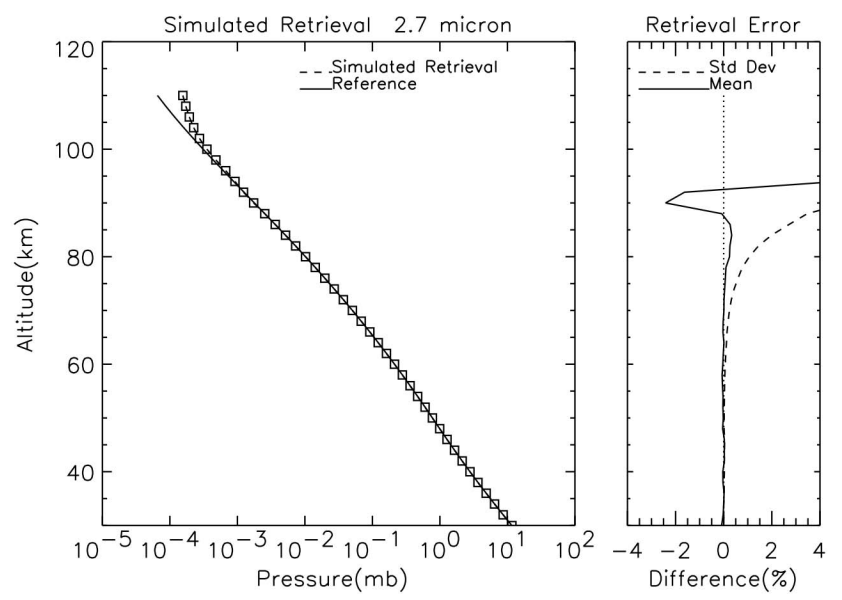

Fig. 14. Same as Fig. 13 but for pressure.
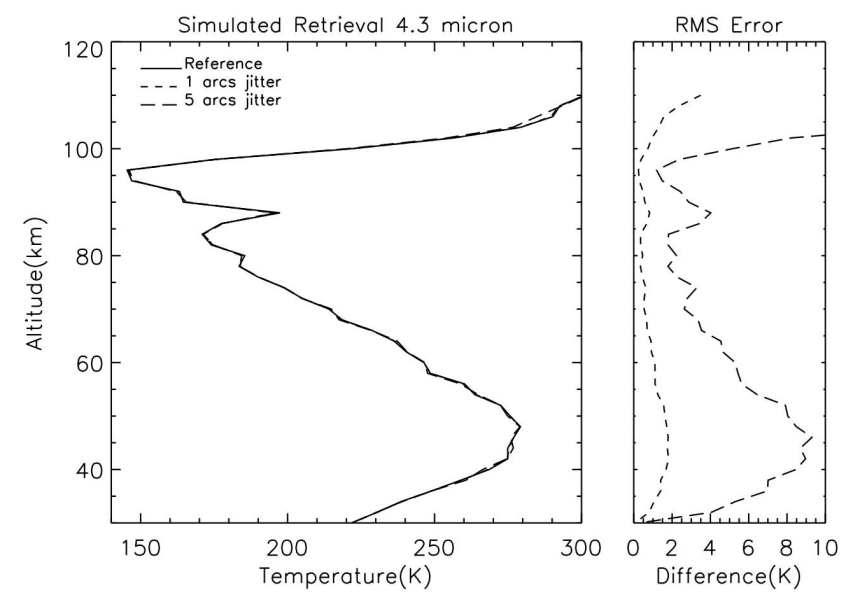

Fig. 15. Impact of random pointing error on retrieved temperature. Right-hand panel shows the RMS difference.

significant vertical structure is used so that the impact of jitter on retrieved structure is also evaluated. These results demonstrate that pointing jitter should be less than 1 arc sec for accurate $(<2 \mathrm{~K}$ error) retrievals (pointing jitter for SOFIE is less than $0.2 \mathrm{arcsec}$ ). Finally, the ability of the $4.3 \mu \mathrm{m}$ retrieval to resolve vertical profile structure is examined. Figure 16 shows a simulated retrieval for an atmosphere with vertical structure on a $2 \mathrm{~km}$ grid. The retrieval starts with an isothermal temperature profile above $z_{0}(30 \mathrm{~km})$ and proceeds with iterative application of algorithm $F$, the lower boundary (conditions at $z_{0}$ ) remains fixed throughout this procedure. In this example, the initial profile is retrieved to within $\pm 2 \mathrm{~K}$ below $105 \mathrm{~km}$, after ten retrieval iterations. For operational application, the retrieval starts from a climatology representative of the measurement location and fewer iterations are typically required.

As mentioned in the introduction, an assumed $\mathrm{CO}_{2}$ mixing ratio is required for the $4.3 \mu \mathrm{m}$ and $2.7 \mu \mathrm{m} T(P)$ retrievals.

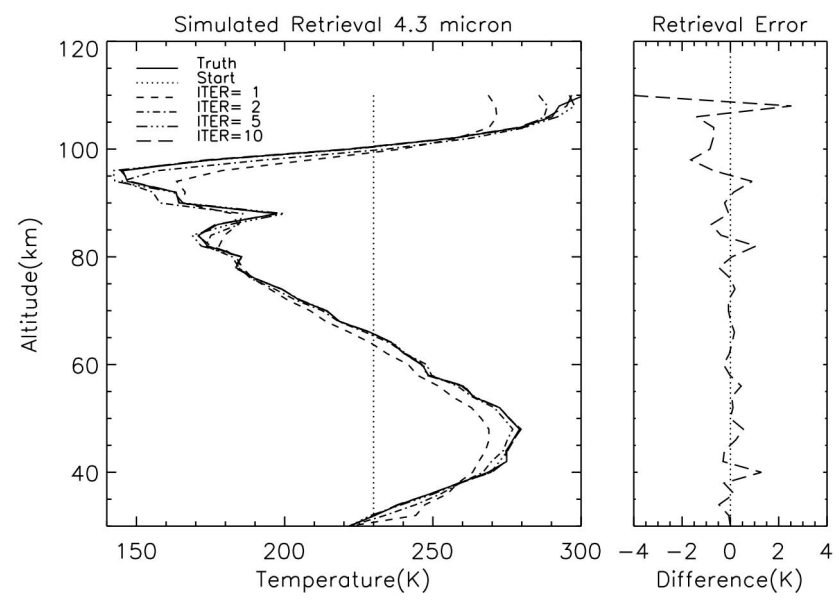

Fig. 16. The iteration sequence for a temperature profile with significant vertical structure. Right-hand panel shows the difference from truth of retrieved profile after 10 iterations.

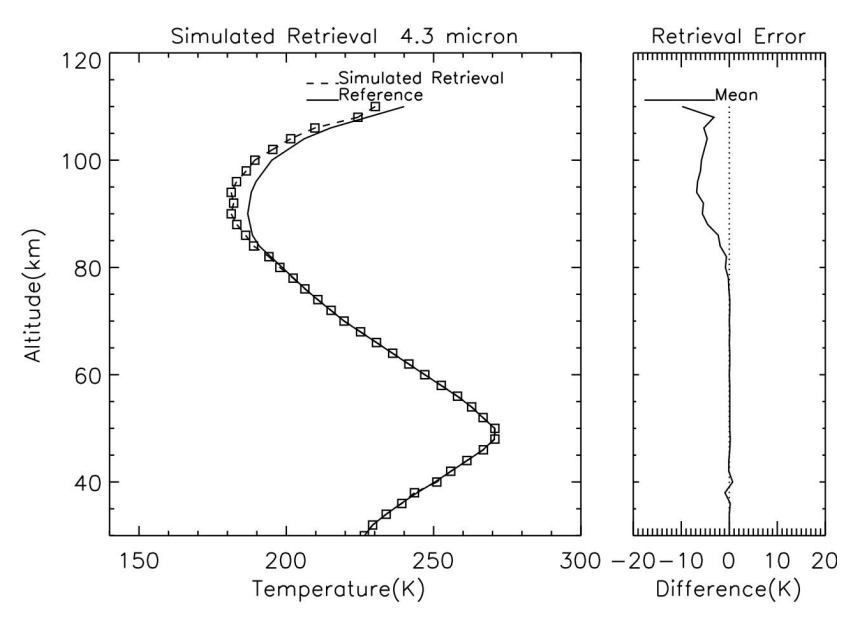

Fig. 17. Impact on the retrieved temperature profile of using the $\mathrm{CO}_{2}$ mixing ratio error shown in Fig. 18. Right-hand panel shows the error in retrieved temperature.

$\mathrm{CO}_{2}$ is well mixed and assumed known to within $1 \%$ in the stratosphere and for some situations (e.g., polar summer) well into the mesosphere. In the middle to upper mesosphere, however, photo-dissociation causes variations in $\mathrm{CO}_{2}$ concentration. Thus the $T(P)$ retrievals from HALOE and the current version (v1.03) of SOFIE, both of which assume $\mathrm{a} \mathrm{CO}_{2}$ profile, can have substantial biases in the middle to upper mesosphere. As an example, Fig. 17 shows impact on the SOFIE $4.3 \mu \mathrm{m}$ temperature retrieval due to an assumed error in $\mathrm{CO}_{2}$ mixing ratio as shown in Fig. 18. This is not necessarily representative of the actual errors in SOFIE data but is meant to demonstrate the sensitivity to this type of error.

There are a number of error mechanisms not discussed above that impact real world results. Most obvious is impact due to absorption by other atmospheric constituents. The 4.3 and $2.7 \mu \mathrm{m}$ bands used in the above analysis are very strong 


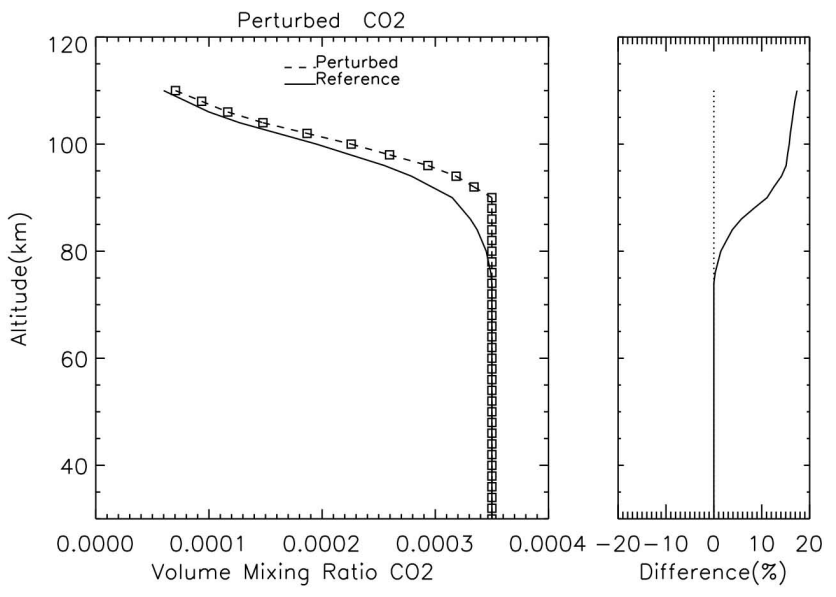

Fig. 18. $\mathrm{CO}_{2}$ mixing ratio error. Right-hand panel shows the $\%$ error.

with mostly minor impact from other constituents, but significant contributions are made by ice particles (polar mesospheric clouds) in both bands and water in the $2.7 \mu \mathrm{m}$ band. These are discussed briefly in Sect. 6, as are errors due to inadequate modeling of absorption line shape, nLTE effects, and instrument field-of-view (FOV).

\section{Multiple channel retrieval simulations}

As seen in Figs. $7-10$, the 4.3 and $2.7 \mu \mathrm{m}$ bands have very different responses to lower boundary pressure errors, which imply that this difference can be used to derive pressure independent from the a-priori temperatures. Since the $2.7 \mu \mathrm{m}$ band is more sensitive to this error, it is used in an iterative procedure to adjust the lower boundary pressure. The $F$ algorithm is used to retrieve temperature and pressure, $T(P)$, from the $4.3 \mu \mathrm{m}$ band using a simulated limb-path transmittance profile with $10^{-5}$ transmittance error and starting from an a-priori lower boundary with $2 \%$ pressure error and $5 \mathrm{~K}$ temperature error (as for Figs. 7-10). The $2.7 \mu \mathrm{m}$ channel is then used to estimate the lower boundary pressure by simulating the $2.7 \mu \mathrm{m}$ channel lower boundary measurements and iterating the pressure to achieve a match of measurement and model. These two procedures $(4.3 T(P)$ retrieval and 2.7 $P_{o}$ retrieval) are iterated until the lower boundary pressure converges. Figures 19 and 20 show the results of a simulation using this procedure. These results are nearly as good as the $4.3 \mu \mathrm{m}$ retrievals with perfect lower boundary knowledge, Figs. 11 and 12.

As shown in the previous section, substantial error in retrieved $T(P)$ can result from inadequate knowledge of the $\mathrm{CO}_{2}$ mixing ratio profile. However, with proper selection of spectral band-pass for the 2.7 and $4.3 \mu \mathrm{m}$ channels, it is possible to retrieve a $\mathrm{CO}_{2}$ mixing ratio profile simultaneously with $T(P)$. Simulations using the SOFIE bands show this

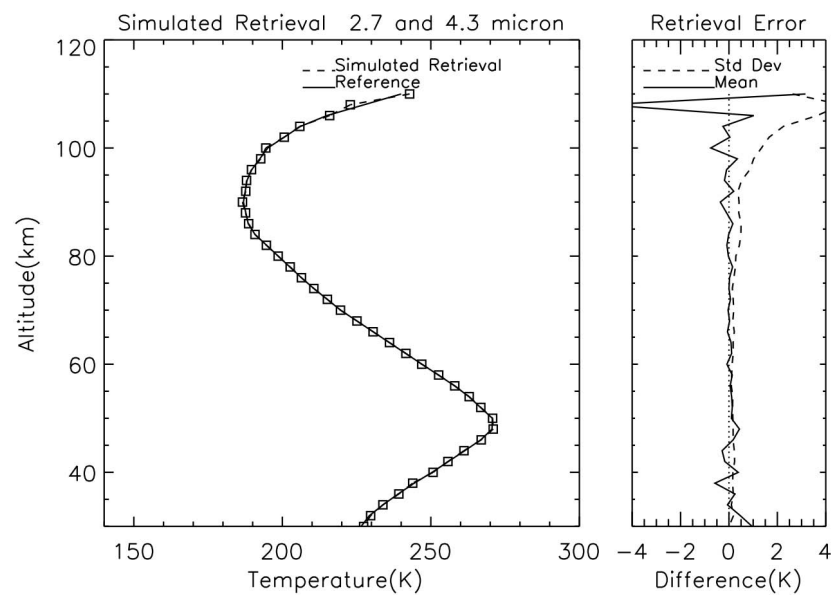

Fig. 19. Temperature results using a two-channel retrieval to overcome lower boundary error of $2 \%$ in pressure and $5 \mathrm{~K}$ in temperature. Right-hand panel shows the mean error and error standard deviation due to $10^{-5}$ random measurement error on broadband averaged transmittance.

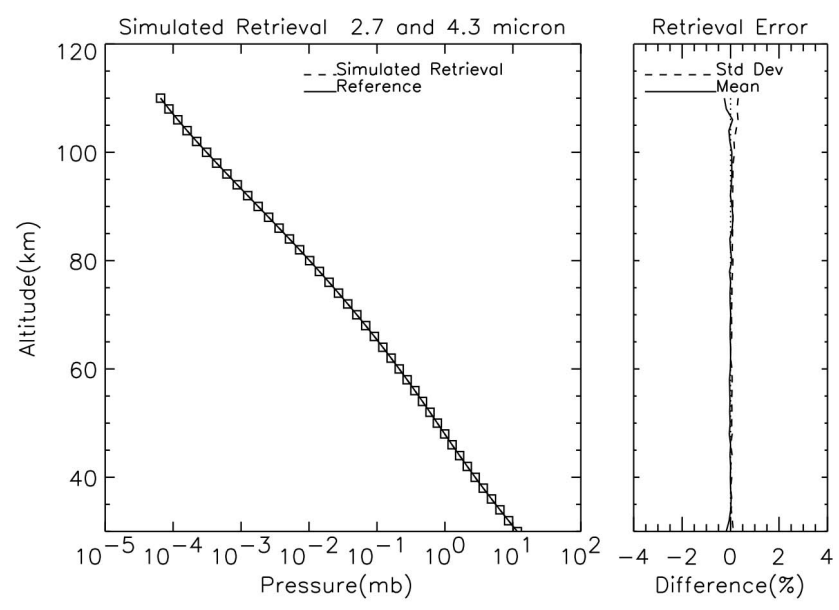

Fig. 20. Same as Fig. 19 but for pressure.

to generally be possible, however, such retrievals are more sensitive to random noise errors than the $T(P)$ only retrieval and there are altitude regions where there is insufficient information to adequately separate $T(P)$ and $\mathrm{CO}_{2}$ mixing ratio information. Figures 21-24 show retrieved profiles of temperature and $\mathrm{CO}_{2}$ mixing ratio for a simultaneous $T(P)$ and $\mathrm{CO}_{2}$ mixing ratio retrieval on simulated signals using the SOFIE bands. This retrieval uses the $F$ algorithm for $T(P)$ but simultaneously retrieves $\mathrm{CO}_{2}$ mixing ratio above $68 \mathrm{~km}$. The plots shown in Figs. 21 and 22 are for a random noise of $10^{-5}$ for both channels, where Figs. 23 and 24 are for a random noise of $2.5 \times 10^{-6}$. Attempts to start the $\mathrm{CO}_{2}$ mixing ratio retrieval at lower altitudes result in large error in the $60-70 \mathrm{~km}$ range (not shown). We are continuing to investigate this and expect to make use of additional information 

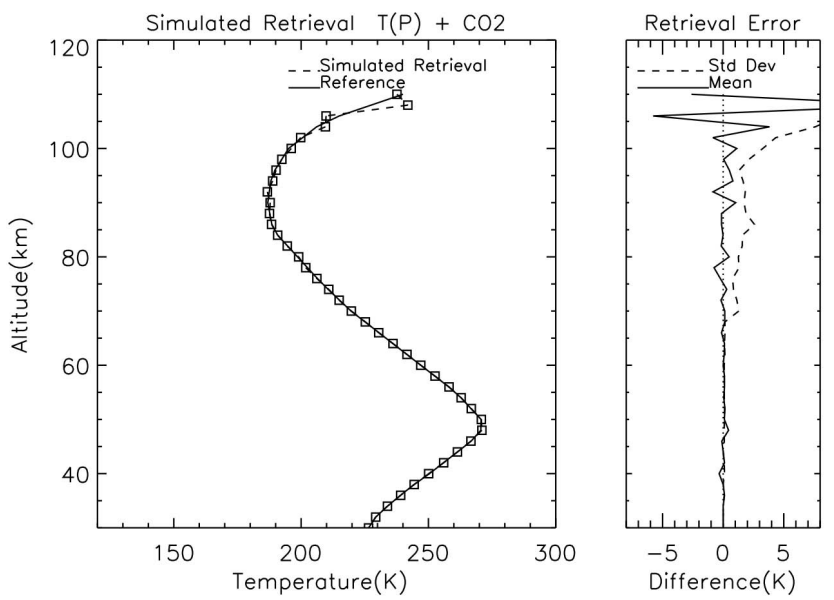

Fig. 21. Temperature profile results from simultaneous $T(P)$ and $\mathrm{CO}_{2}$ mixing ratio retrieval using 2 channels in the vicinity of 4.3 and $2.7 \mu \mathrm{m}$ with $10^{-5}$ random noise. Right-hand panel shows the mean error and error standard deviation due to $10^{-5}$ random measurement error on broadband averaged transmittance.

including density constraints determined from the refractive bending angle data available from SOFIE to improve these results. It is also likely that optimizing the band-pass selection could improve these results and that should be investigated for application to future missions. Specifically, for best results, one of the bands should exhibit significantly more sensitivity to temperature than the other. Though, this is the case for the $4.3 \mu \mathrm{m}$ band versus the $2.7 \mu \mathrm{m}$ band used for SOFIE, there likely exists band pairs that would perform better. The results shown in Figs. 21-24 may seem inconsistent with results from Fig. 13, where the 2.7 channel $T(P)$ retrieval fails above $90 \mathrm{~km}$. This $T(P)$ failure can be explained by instabilities near altitudes where the temperature sensitivity is too small. However, in the $T(P), \mathrm{CO}_{2}$ retrieval, the $2.7 \mu \mathrm{m}$ channel is used only for retrieving $\mathrm{CO}_{2}$ concentration, and the $4.3 \mu \mathrm{m}$ channel is used for retrieving temperature. The $2.7 \mu \mathrm{m}$ channel sensitivity to $\mathrm{CO}_{2}$ is evident from $I$ in Fig. 4; that curve shows impact of a $1 \mathrm{~K}$ temperature change on density and is equivalent to the impact of less than a $1 \%$ change in $\mathrm{CO}_{2}$ concentration.

\section{SOFIE approach}

SOFIE is a broadband occultation sensor that employs 10 single detector channels as well as a high resolution focal plane array (FPA) that is used to track the sun. $\mathrm{HgCdTe}$ detectors are used to sense the 4.3 and $2.7 \mu \mathrm{m}$ bands. The detector FOV for these channels at $83 \mathrm{~km}$ tangent point is approximately $1.6 \mathrm{~km}$ vertical by $4.5 \mathrm{~km}$ horizontal with oversampling to about $0.2 \mathrm{~km}$ in the vertical. More details on SOFIE, including detailed channel information, can be found at the following web-site: http://sofie.gats-inc.com/
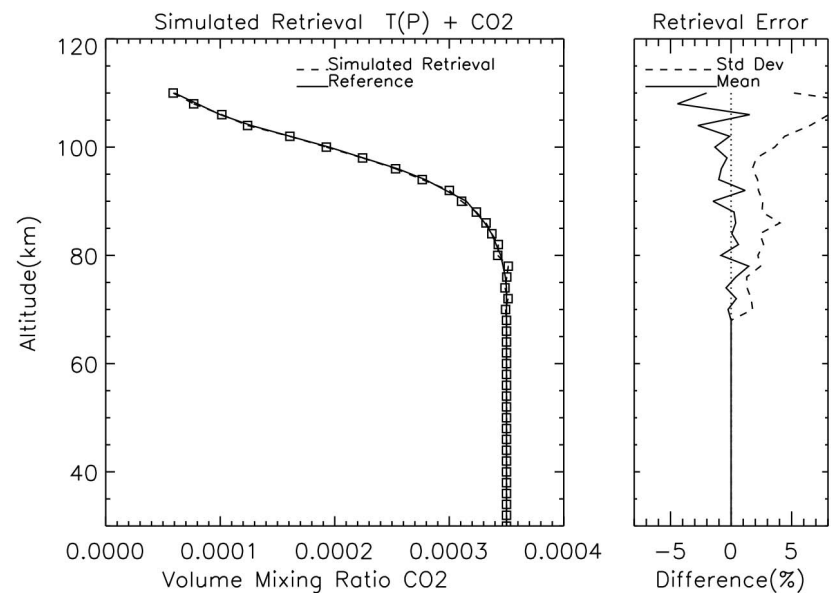

Fig. 22. Same as Fig. 21 but retrieved $\mathrm{CO}_{2}$ mixing ratio profile.
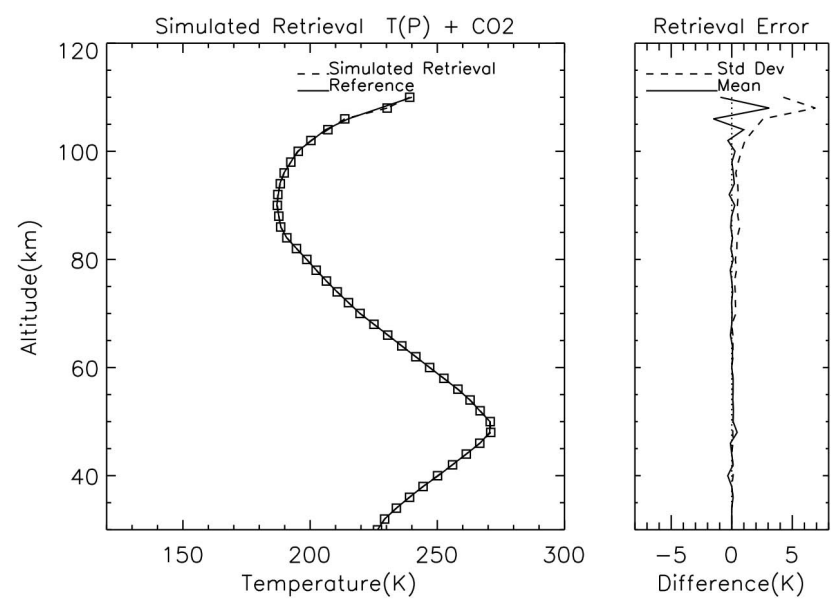

Fig. 23. Same as Fig. 21 but using $2.5 \times 10^{-6}$ random noise.

sofie/index.php. We note that SOFIE employs several channels for the detection and characterization of polar mesospheric clouds (PMC) as discussed in Hervig et al. (2009). These data are used to correct for cloud extinction in the retrieval of $T(P)$ from the $4.3 \mu \mathrm{m}$ channel. We also note that, though the absorbing (lower) states of the $4.3 \mu \mathrm{m}$ band are in local thermodynamic equilibrium throughout the stratosphere and lower to middle mesosphere, the lower energy state populations of several hot-band transitions are impacted by nLTE processes in the cold polar summer mesopause region and nLTE processes are important for many bands in the lower thermosphere. Starting with SOFIE version 1.02, nLTE effects are explicitly modeled using the $\mathrm{CO}_{2}$ nLTE models developed for SABER (Lopez-Puertas and Taylor, 2001; Mertens et al., 2001; and Kutepov et al., 2006). Note that the lower energy states of concern for the SOFIE $4.3 \mu \mathrm{m}$ band are upper energy states for transitions of concern in the emission of the SABER $15 \mu \mathrm{m}$ bands. We briefly discuss both PMC correction and nLTE at the end of this section. 

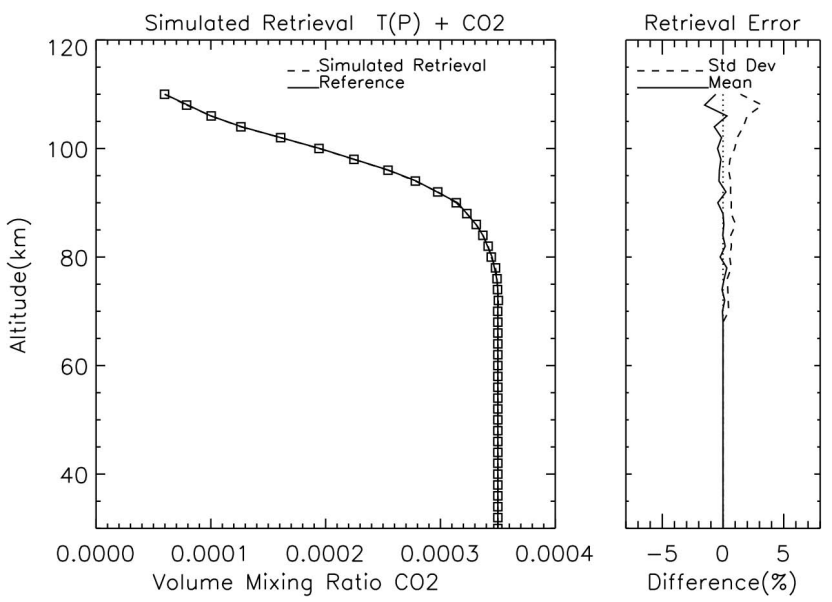

Fig. 24. Same as Fig. 23 but retrieved $\mathrm{CO}_{2}$ mixing ratio profile.

The SOFIE $4.3 \mu \mathrm{m}$ temperature retrieval algorithm uses the upward retrieval technique designated by the $F$ curves in Fig. 3. These retrievals start at $30 \mathrm{~km}$ and use NCEP data to constrain the lower boundary. The retrievals operate on a $2 \mathrm{~km}$ vertical grid with multiple interleaves of the data combined to achieve the final high resolution output data. Random noise is approximately $10^{-5}$ (consistent with the random error used in Figs. 11-14) providing a signal to noise ratio (SNR) of nearly 100000 in the lower stratosphere and about 500 at $100 \mathrm{~km}$.

The high resolution FPA is employed by SOFIE to precisely track the Sun during an event, providing a very accurate measurement of the solar image as a function of altitude. Using a new technique developed for SOFIE, limb refraction profiles can be inferred to a precision of $0.02 \mathrm{arcsec}$ from solar extent data determined from the measured solar image data (Gordley et al., 2009a). This precision is far better than the $<0.2$ arc sec jitter evident in the science channels because many pixels from the FPA are used to determine upper and lower edges of the solar image. These extremely precise refraction angle data are used to retrieve density profiles, which are then used to retrieve $T(P)$ with methods similar to those described in Ward and Hermann (1998). Density is determined directly from the measured refraction angle profile and $T(P)$ is determined from the density profile using the ideal gas law and hydrostatic integration. The details of the procedure used to perform these retrievals are not presented here, but we note that the primary limitations of such retrievals are pointing accuracy and upper boundary error. Pointing errors and errors in the upper boundary refraction angle lead to error in the retrieved density profile, which then leads to error in retrieved $T(P)$. Also, retrieved $T(P)$ is impacted by error in the upper boundary temperature.

With the precision obtained by the SOFIE refraction measurements, upper boundary error is the primary source of error for retrieved $T(P)$ in the stratosphere. The results

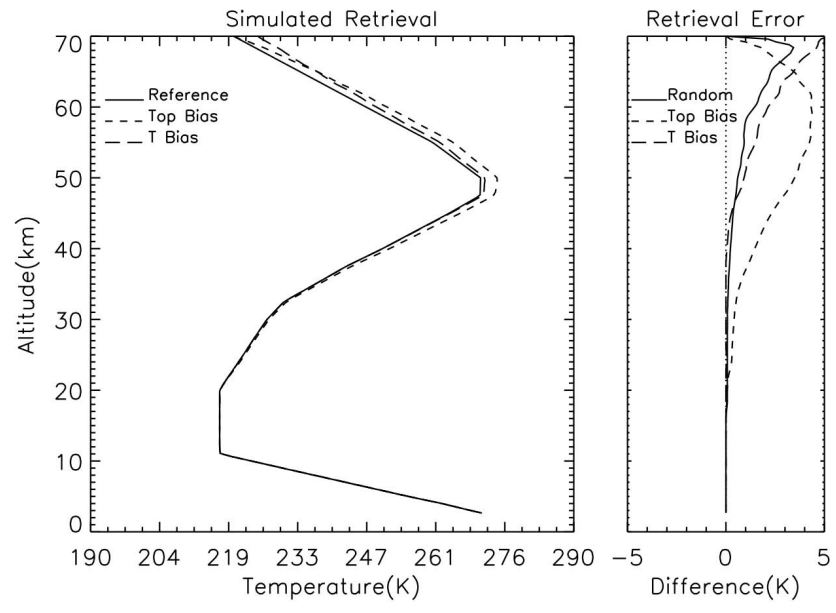

Fig. 25. Impact of random pointing errors and top boundary errors on retrieved temperature, long dashed line shows impact of $5 \mathrm{~K}$ upper boundary temperature error, short dashed lines shows impact of $5 \%$ upper boundary error on refraction angle. Right-hand panel shows the errors, solid line in right-hand panel shows impact of random pointing error of $0.02 \mathrm{arc} \mathrm{sec}$.

of detailed simulations are presented here to illustrate the relative importance of the various errors on retrieved density and temperature. Figure 25 shows the impact of a $5 \mathrm{~K}$ upper boundary temperature error and a $5 \%$ refraction angle error as well as uncertainty due to 0.02 arc sec random pointing error on retrieved temperature. Figure 26 shows the impact of $5 \%$ upper boundary refraction angle error and 0.02 arc sec random pointing error on retrieved density. For SOFIE, uncertainties due to random pointing error and upper boundary error are greatly reduced by fitting the measured refraction data to reduce noise, by merging measured refraction data with refraction determined from simulation of the $4.3 \mu \mathrm{m}$ retrieved $T(P)$ profile using a gradual transition from about $50 \mathrm{~km}$ to about $70 \mathrm{~km}$, and by using the $4.3 \mu \mathrm{m}$ retrieved $T(P)$ to constrain the upper boundary (Gordley et al., 2009a). Starting with version 1.03 SOFIE, a refraction based retrieval is used in conjunction with the $4.3 \mu \mathrm{m}$ retrieval to determine the final output $T(P)$. Version $1.03 T(P)$ below $50 \mathrm{~km}$ is entirely from refraction measurements and is a combination of refraction and $4.3 \mu \mathrm{m} \mathrm{CO} \mathrm{CO}_{2}$ measurements between 50 and $70 \mathrm{~km}$. This approach greatly reduces upper boundary errors for the refraction-based retrievals and also eliminates the lower boundary errors seen in Figs. 7-10. Figure 27 shows a comparison of v1.03 and v1.022 data for the period 8-14 July 2009 , the mean profiles and standard deviations are determined from 83 profile pairs.

The results shown in Fig. 27 also give an example of the utility of the refraction measurement for diagnosing problems with the early versions of the SOFIE $4.3 \mu \mathrm{m}$ retrieved temperature. The observed bias between the $4.3 \mu \mathrm{m}$ retrieval and the refraction-based retrieval in the 40 to $50 \mathrm{~km}$ region was determined to be due to a combination of FOV 


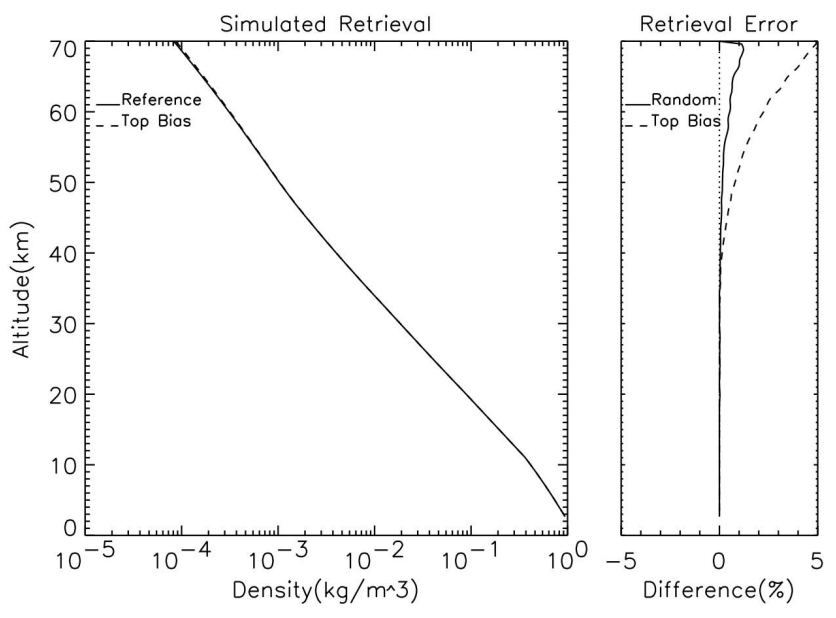

Fig. 26. Same as Fig. 25 except impact on retrieved density from random pointing error of $0.02 \mathrm{arcsec}$ and top boundary refraction angle error of $5 \%$.

characterization and line mixing effects in the $4.3 \mu \mathrm{m} \mathrm{CO} 2$ band, corrected for version 1.03. Line mixing is modeled using the AER v2.2 spectroscopic data supplied by Atmospheric and Environmental Research, Inc., http://rtweb.aer. com/line_param_frame.html. The $\mathrm{CO}_{2}$ line parameters in this data are from HITRAN 2000 (Rothman et al., 2003), with the addition of line coupling parameters determined from calculations using the software and database package of Niro et al. (2005).

Version 1.03 SOFIE uses $\mathrm{CO}_{2}$ mixing ratio profiles from the Whole Atmosphere Community Climate Model (Garcia et al, 2007). For future SOFIE versions, we are investigating use of the SOFIE $2.7 \mu \mathrm{m}$ channel in the retrieval of $\mathrm{CO}_{2}$ mixing ratio as described in Sect. 5 with additional solution constraints provided by the refraction based $T(P)$ retrieval. We have not investigated use of this channel along with the $4.3 \mu \mathrm{m}$ channel for determination of lower boundary $T(P)$, also described in Sect. 5. This is primarily because of the superior information contained in the refraction data for this purpose.

The procedure used in v1.03 provides a $T(P)$ profile with $\sim 2 \mathrm{~K}$ precision from cloud top or $5 \mathrm{~km}$, whichever is higher, to $90 \mathrm{~km}$. These data are currently thought to be generally accurate to within $3 \mathrm{~K}$ up to about $80 \mathrm{~km}$, but as shown in Sect. $5, \mathrm{CO}_{2}$ profile errors may have significant impact to as low as $60 \mathrm{~km}$. And, as previously noted, ice cloud contamination in the polar summer mesopause region has significant contribution to total path extinction which must be addressed. SOFIE PMC measurements are used to correct for ice cloud contribution in the $4.3 \mu \mathrm{m}$ channel. Figure 28 shows the mean impact of such correction on the temperature retrieval for the 8-14 July 2009 period. The average impact is approximately $5 \mathrm{~K}$ at the cloud extinction peak altitude though thick clouds can have impact as high as $10 \mathrm{~K}$. We

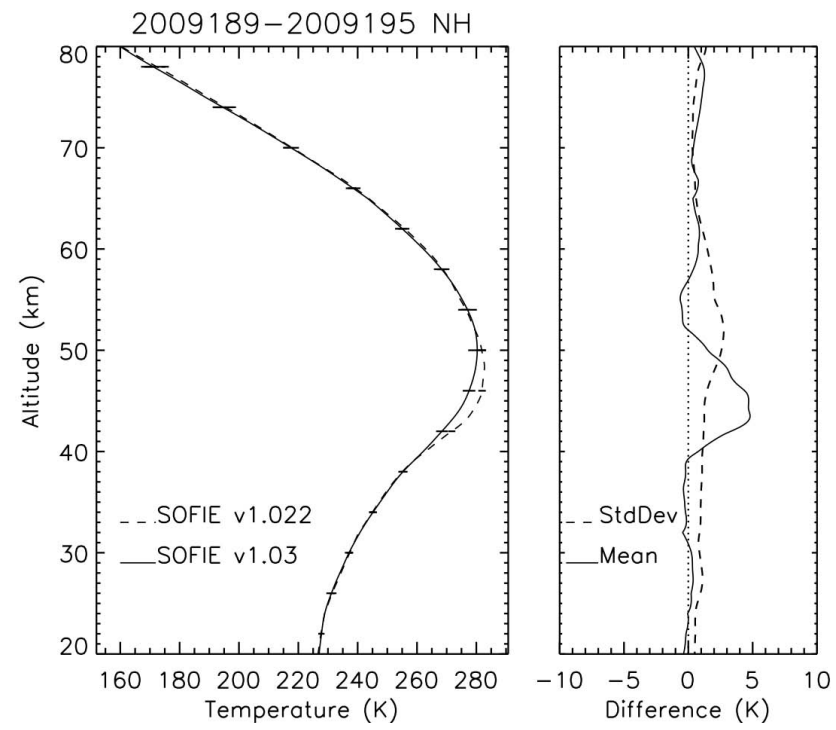

Fig. 27. SOFIE version 1.03 data compared to version 1.022 for the period 8-14 July 2009 . Note the difference in the $40-50 \mathrm{~km}$ region. Right-hand panel shows the mean difference and difference standard deviation.

currently estimate the extinction correction to be better than $20 \%$ resulting in typically less than $2 \mathrm{~K}$ residual error in retrieved temperature. Also, errors in parameters used by the $\mathrm{CO}_{2} 4.3 \mu \mathrm{m}$ nLTE model limit accuracy above $80 \mathrm{~km}$. For example, error in concentration of $\mathrm{O}$ can have large impact above about $85 \mathrm{~km}$ due to its important quenching role. Likewise, error in quenching or excitation rates can have large impact as well. Though we do not here present a detailed error analysis of such effects, it should be noted that accuracy in retrieved $T(P)$ in the lower thermosphere and in the very cold polar summer mesopause region is largely determined by accuracy of the inputs used in the nLTE model. The impact of such errors may approach $5 \mathrm{~K}$ in the polar summer mesopause region and $10 \mathrm{~K}$ in the lower thermosphere.

\section{SOFIE results}

This section discusses comparisons of version 1.03 SOFIE $T(P)$ to that derived from other remote sensors. Included are comparisons to correlative data from the Sounding of the Atmosphere using Broadband Emission Radiometry (SABER) instrument (Russell et al., 1999), the Atmosphere Chemistry Experiment (ACE) instrument (Bernath et al., 2005), and the Microwave Limb Sounder (MLS) instrument (Waters et al., 1999). The primary goals of the SOFIE experiment are better characterization of the polar summer (PS) mesosphere and better understanding of PMC formation. These goals led to an observation strategy that provides measurements in two broad latitude regions, $65^{\circ}-83^{\circ} \mathrm{N}$ and $65^{\circ}-83^{\circ} \mathrm{S}$, see Fig. 29 . Since two terminator events are available for each orbit and 

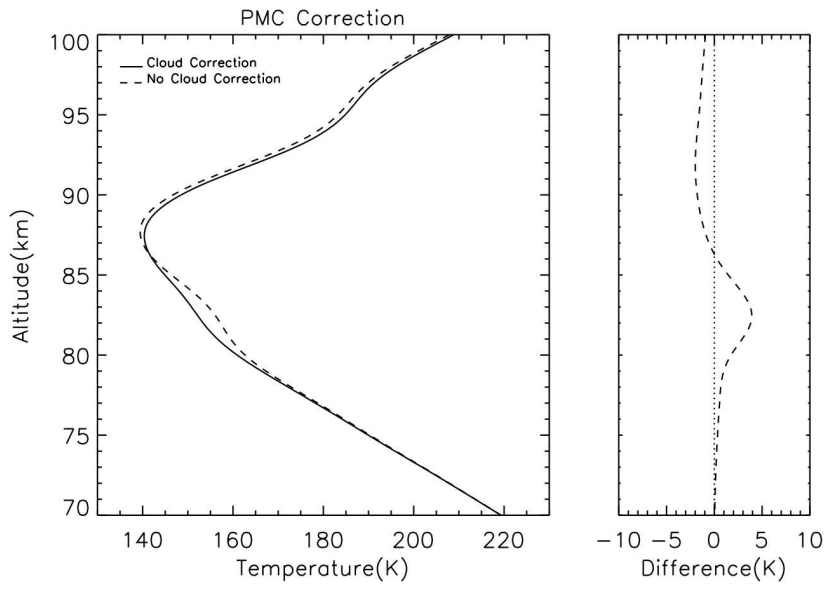

Fig. 28. Impact of PMC correction, right-hand panel shows the difference.

since observations are made year round, polar winter (PW) and equinox periods are also available for comparison. First, we choose a PS comparison period that gives numerous coincidence profiles for all of the instruments. SABER and MLS have global coverage and typically provide excellent coincidence opportunities, but ACE is a solar occultation experiment and so provides fewer coincidence opportunities. There are 3 Northern Hemisphere $(\mathrm{NH})$ and 2 Southern Hemisphere ( $\mathrm{SH}$ ) PS periods that are available for all four datasets. We have selected a period that has the most coincidences with ACE at the heart of the PS season, the week of 8-14 July 2009. We have also selected a PW period with numerous ACE coincidences, the week of 20-26 February 2009. This period is toward the end of a dynamic period of recovery from a very intense stratospheric sudden warming and the stratopause is still elevated to roughly $80 \mathrm{~km}$ altitude. Figures 30 and 31 show the comparisons, the following sub-sections discuss results for each comparison dataset. These comparisons are only meant to introduce the current SOFIE results and are not meant to be a rigorous validation. A thorough validation effort is underway using more extensive data from new versions of the ACE (3.0) and SOFIE (1.1) data currently being processed. Also, note that a reprocessing of the SABER data is planned for late 2011 and more extensive comparisons will be made when those data become available.

\subsection{Comparisons to SABER}

For this comparison we compare the most recent production version, 1.07, of the SABER data to version 1.03 SOFIE. The temperature product for this version of SABER data is discussed in Remsberg et al. (2008). SABER, unlike SOFIE, is an emission experiment that uses atmospheric emission originating primarily from the $\nu 2$ band of $\mathrm{CO}_{2}$ to derive $T(P)$. These data sets therefore have independent instrument char-
SOFIE Latitude Coverage

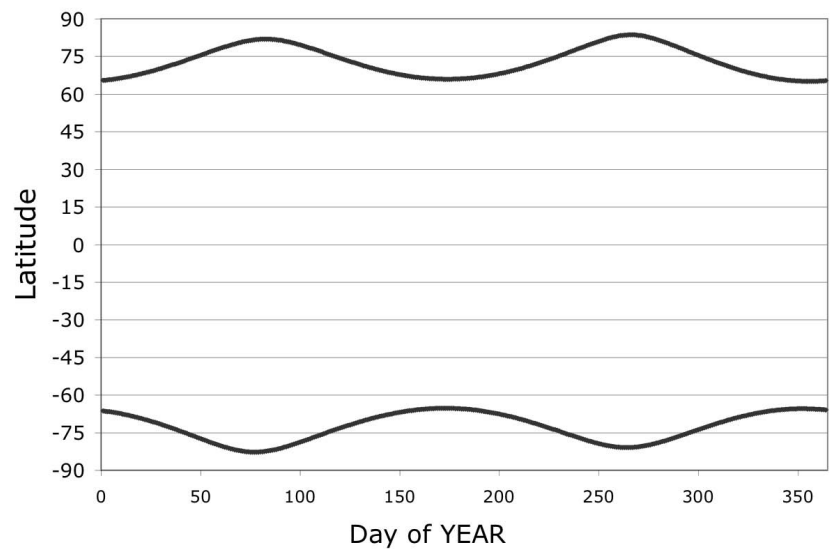

Fig. 29. SOFIE tangent-point latitudes.

acteristics, rely on different measurement techniques $(4.3 \mu \mathrm{m}$ transmission vs. $15 \mu \mathrm{m}$ emission), and use different analysis methods. For the comparisons shown in this and the following sections, profile pairs were selected with a maximum latitude difference of $2^{\circ}$, maximum longitude difference of $20^{\circ}$, and maximum time difference of $4 \mathrm{~h}$. Figure 30 gives comparisons of mean SOFIE temperature measurements (the solid black curve in the left hand panel) to coincident profiles from SABER (red curves), for the period 8-14 July 2009. These comparisons are for 70 coincidence profiles with mean latitude difference of $0.8^{\circ}$, mean longitude difference of $5.4^{\circ}$, and mean time difference of $40 \mathrm{~min}$. The SOFIE and SABER mean profiles generally agree very well $( \pm 3 \mathrm{~K})$ over the range $0.1-100 \mathrm{mb}$ for the high latitude $(\sim 67 \mathrm{~N})$ summer data shown in Fig. 30. As reported in Remsberg et al. (2008), the SABER profiles over this altitude range have approximately $1-2 \mathrm{~K}$ precision but may be biased $2-3 \mathrm{~K}$ warm in the lower stratosphere and $1-3 \mathrm{~K}$ cold in the upper stratosphere to lower mesosphere (for conditions where the stratopause is in the typical $1 \mathrm{mb}$ region). As stated previously, SOFIE $T(P)$ has approximately $2 \mathrm{~K}$ uncertainty over this altitude range so the agreement seen in Fig. 30 is within the combined uncertainties.

Figure 31 (red curves) gives a similar comparison for the period 20-26 February 2009 using 46 coincidence profiles with mean latitude difference of $1.0^{\circ}$, mean longitude difference of $9.1^{\circ}$, and mean time difference of $3.0 \mathrm{~h}$. The agreement over the range $0.1-100 \mathrm{mb}$ for the high latitude $(\sim 77 \mathrm{~N})$ winter data shown in this figure is also very good. Results at pressures in the range 0.1 to $0.01 \mathrm{mb}$ are somewhat worse for both periods, for the February data this could be due to larger dynamic activity in this region. This period follows what appears to be one of the strongest stratospheric sudden warmings (SSW) on record (Manney et al., 2009). The high latitude stratopause reformed at approximately $80 \mathrm{~km}$ in early February following this SSW and remained 


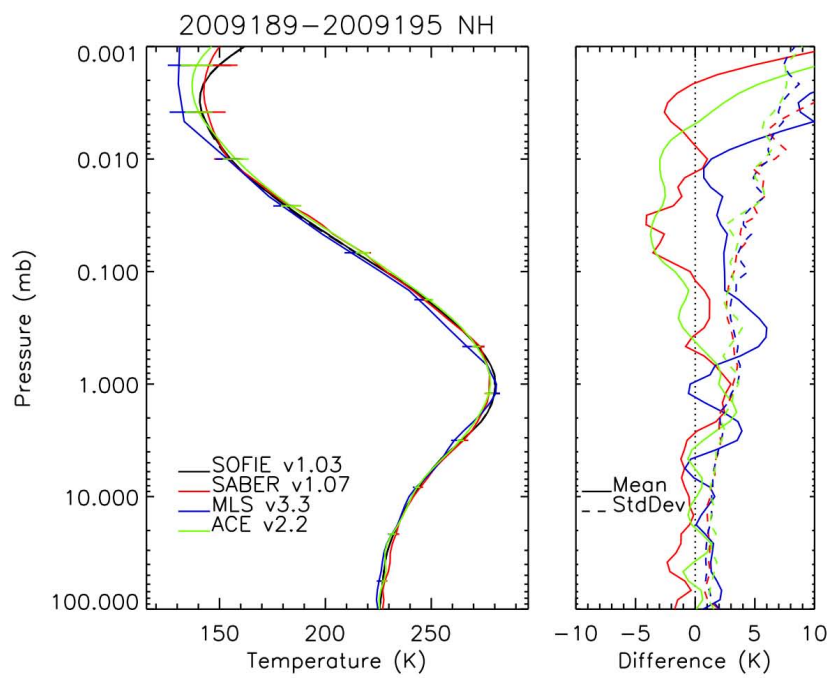

Fig. 30. Comparison between mean SOFIE (black), SABER (red), ACE (green), and MLS (blue) profiles for coincident Northern Hemisphere (NH) data for the period 8-14 July 2009, left-hand panel shows the mean profiles, right-hand panel shows the mean difference and difference standard deviation profiles (SOFIE - each of the others).

at elevated altitudes until approximately mid-March. Interestingly, SABER and SOFIE both exhibit the elevated stratopause at about $0.005 \mathrm{mb}$ (MLS and ACE show it at about $0.01 \mathrm{mb}$ ). For both periods, the differences at pressures below $0.01 \mathrm{mb}$ can be large and are likely due to among other things, $\mathrm{CO}_{2}$ profile differences, accumulated pressure errors, $\mathrm{O}$ concentration differences (needed by the nLTE models), and different atmospheric dynamics in the coincidence pairs (a larger problem for the high latitude winter comparisons in Fig. 31). For SOFIE data with strong PMC contamination, there may also be error of $1-2 \mathrm{~K}$ in the $80-85 \mathrm{~km}$ region due to residuals in the ice cloud correction.

\subsection{Comparisons to $\mathrm{ACE}$}

SOFIE is compared to version 2.2 of the ACE dataset. Version 3.0 is in production at this time, and a more complete comparison using this updated dataset will be carried out in the near future. The temperature product for ACE version 2.2 is discussed in Sica et al. (2008). ACE is a solar occultation sensor, but rather than the broadband measurements used by SOFIE, ACE derives temperature from its Fourier Transform Spectrometer (FTS) instrument that covers the spectral region 750 to $4400 \mathrm{~cm}^{-1}$. The atmospheric temperature and pressure retrieval uses micro-windows that are primarily attenuated by $\mathrm{CO}_{2}$ absorption. As described in Sica et al. (2008), the ACE temperature data can exhibit large unphysical vertical oscillations in the mesosphere and to a lesser extent in the stratosphere. These oscillations appear to be caused by retrieval artifacts that will be addressed

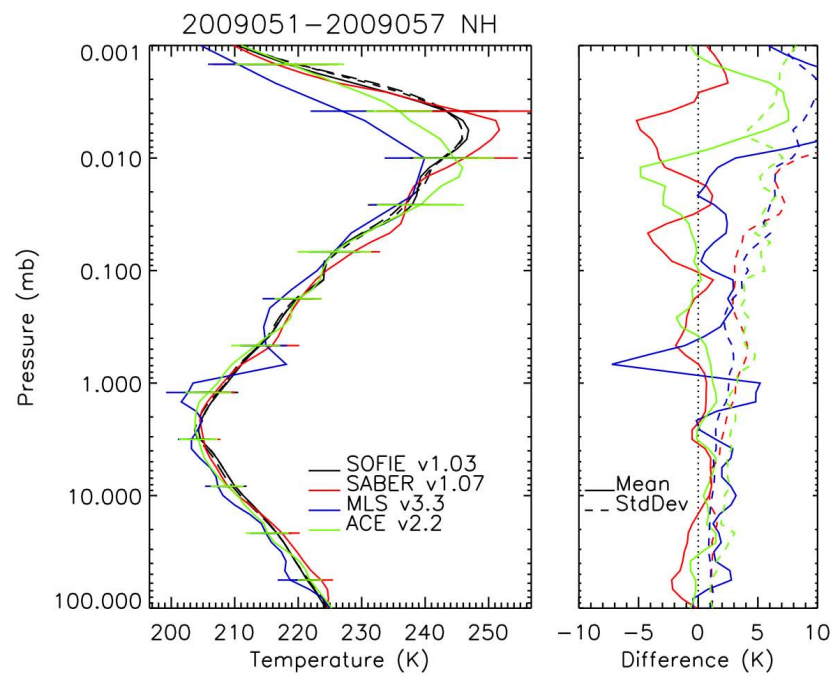

Fig. 31. Comparison between mean SOFIE (black), SABER (red), ACE (green), and MLS (blue) profiles for coincident Northern Hemisphere (NH) data for the period 20-26 February 2009, lefthand panel shows the mean profiles, right-hand panel shows the mean difference and difference standard deviation profiles (SOFIE - each of the others).

in the next version of ACE and occur in only a small fraction of the data. In general, with the exception of these few spurious profiles, the ACE temperatures have a precision of roughly $2 \mathrm{~K}$ over the altitude range compared in this paper. Also, systematic errors are thought to be small $(<2 \mathrm{~K})$ in the stratosphere but perhaps somewhat larger in the mesosphere, particularly above $70 \mathrm{~km}$. Because of the potential for unphysical profiles, the comparisons shown in this paper use only the ACE data that pass a screening procedure that rejects all events with RMS differences greater than $10 \mathrm{~K}$ for that profile compared to the mean profile for a given coincidence set. The green curves in Figs. 30 and 31 show the comparisons of the screened ACE data to SOFIE (the longdashed black curve in the left hand panel, largely obscured by the solid curve) for the same periods compared to SABER. The comparisons in Fig. 30 are for 37 coincidence profiles with mean latitude difference of $0.6^{\circ}$, mean longitude difference of $6.6^{\circ}$, and mean time difference of $1.7 \mathrm{~h}$. The comparisons in Fig. 31 are for 40 coincidence profiles with mean latitude difference of $1.4^{\circ}$, mean longitude difference of $6.6^{\circ}$, and mean time difference of $30 \mathrm{~min}$. The comparison between ACE and SOFIE is similar to that seen for SABER, with agreement generally within $3 \mathrm{~K}$ for the stratosphere and well into the mesosphere. These differences are well within expected errors of the two instruments. Differences in the upper mesosphere are larger, as expected, for reasons discussed in Sect. 7.1 and for the February comparison ACE shows a reformed stratopause at about $0.012 \mathrm{mb}$ rather than the $0.005 \mathrm{mb}$ exhibited by SOFIE and SABER. Note that the ACE retrievals, unlike both v1.07 SABER and v1.03 SOFIE, 
use retrieved $\mathrm{CO}_{2}$ VMR profiles. As discussed in Sect. 5, large errors in the $\mathrm{CO}_{2}$ profile can lead to large errors in retrieved $T(P)$ for SOFIE as well as for SABER. This may partially explain some of the difference for pressures below $0.1 \mathrm{mb}$.

\subsection{Comparisons to MLS}

SOFIE is next compared to the most recent production version, 3.3, of the Earth Observing System (EOS) MLS data. The temperature product for the previous version (2.2) of EOS MLS is discussed in Schwartz et al. (2008). For the data of interest in this paper, version 3.3 MLS only differs significantly from 2.2 in the pressure range $1-20 \mathrm{mb}$ where 3.3 uses more grid points in its analysis. MLS is a microwave instrument that uses emission from the $\mathrm{O}_{2}$ line at $118 \mathrm{GHz}$ to retrieve $T(P)$ at the altitudes compared in this paper. In general, the MLS temperatures have a precision of 1.0-2.5 K over this altitude range and systematic errors of $2-3 \mathrm{~K}$ with an oscillatory vertical structure. This is a known problem with instrument gain and is expected to be corrected in a future version of the AURA MLS data. The systematic errors may be worse for some situations, as exemplified in the comparisons performed here. Figures 30 and 31 show the comparisons of MLS (blue curves) to SOFIE (short-dashed black curve in the left hand panels, largely obscured by the solid curve). The comparisons in Fig. 30 are for 82 coincidence profiles with mean latitude difference of $0.3^{\circ}$, mean longitude difference of $9.8^{\circ}$, and mean time difference of $3.2 \mathrm{~h}$. The comparisons in Fig. 31 are for 87 coincidence profiles with mean latitude difference of $0.4^{\circ}$, mean longitude difference of $7.9^{\circ}$, and mean time difference of $3.3 \mathrm{~h}$. Ignoring the anomalous results in the 0.5 to $2 \mathrm{mb}$ region, the February comparisons shown in Fig. 31 are very good, within 3 or $4 \mathrm{~K}$ up to about $0.01 \mathrm{mb}$. The MLS data shows a reformed stratopause at about $0.01 \mathrm{mb}$, similar to the $0.012 \mathrm{mb}$ seen for ACE. The July comparisons shown in Fig. 30 are also generally good over the same pressure range if the region from 0.2 to $3 \mathrm{mb}$ is excluded. Though the data from 0.2 to $3 \mathrm{mb}$ is not as obviously anomalous as that seen in the February data, it does fit the description of the biases due to the gain errors described in Schwartz et al. (2008). As for the other comparisons, differences below $0.01 \mathrm{mb}$ can be large.

\section{Summary}

The success of the HALOE and SOFIE experiments demonstrate that broadband solar occultation measurements can be used to accurately retrieve atmospheric $T(P)$ profiles. For this paper we presented some subtleties inherent in such retrievals and discussed the procedures used in the HALOE and SOFIE data analyses. We also presented investigations of the impact of several major error mechanisms and demonstrated the high quality results that can be achieved using the high precision pointing and transmittance measurements made by SOFIE. Finally, we presented limited comparisons of SOFIE version 1.03 production data to other validated satellite datasets. The SOFIE results include, for the first time, excellent $T(P)$ retrievals throughout the stratosphere and even into the lower mesosphere using atmospheric refraction determined from broadband solar occultation measurements. Work is continuing on the SOFIE project with planned inclusion of a simultaneous retrieval of $\mathrm{CO}_{2}$ mixing ratio profiles.

Acknowledgements. This work has been partially funded by subcontract number 03-11 from Hampton University in support of the AIM Mission under the prime contract number NAS5-03132 NASA SMEX program.

Edited by: C. von Savigny

\section{References}

Bernath, P. F., McElroy, C. T., Abrams, M. C., Boone, C. D., Butler, M., Camy-Peyret, C., Carleer, M., Clerbaux, C., Coheur, P. F., Colin, R., DeCola, P., DeMazière, M., Drummond, J. R., Dufour, D., Evans, W. F. J., Fast, H., Fussen, D., Gilbert, K., Jennings, D. E., Llewellyn, E. J., Lowe, R. P., Mahieu, E., McConnell, J. C., McHugh, M., McLeod, S. D., Michaud, R., Midwinter, C., Nassar, R., Nichitiu, F., Nowlan, C., Rinsland, C. P., Rochon, Y. J., Rowlands, N., Semeniuk, K., Simon, P., Skelton, R., Sloan, J. J., Soucy, M.-A., Strong, K., Tremblay, P., Turnbull, D., Walker, K. A., Walkty, I., Wardle, D. A., Wehrle, V., Zander, R., and Zou, J.: Atmospheric Chemistry Experiment (ACE): mission overview, Geophys. Res. Lett., 32, L15S01, doi:10.1029/2005GL022386, 2005.

Garcia, R. R., Marsh, D. R., Kinnison, D. E., Boville, B. A., and Sassi, F.: Simulations of secular trends in the middle atmosphere, 1950-2003, J. Geophys. Res., 112, D09301, doi:10.1029/2006JD007485, 2007.

Gordley, L. L., Marshall, B. T., and Chu, D. A.: LINEPAK: algorithms for modeling spectral transmittance and radiance, J. Quant. Spectrosc. Ra., 52(5), 563-580, 1994.

Gordley, L. L., Burton, J. C., Marshall, B. T., McHugh, M. J., Deaver, L. E., Nelsen, J., Russell III, J. M., and Bailey, S.: High precision refraction measurements by solar imaging during occultation: results from SOFIE, Appl. Optics, 48(25), 4814-4825, doi:10.1364/AO.48.004814, 2009a.

Gordley, L. L., Hervig, M. E., Fish, C., Russell III, J. M., Bailey, S., Cook, J., Hansen, S., Shumway, A., Paxton, G. J., Deaver, L. E., Marshall, B. T., Burton, J. C., Magill, B., Brown, C., Thompson, R. E., and Kemp, J.: The solar occultation for ice experiment, J. Atmos. Sol.-Terr. Phy., 71(3-4), 300-315, 2009b.

Hervig, M. E., Russell III, J. M., Gordley, L. L., Drayson, S. R., Stone, K., Thompson, R. E., Gelman, M. E., McDermid, I. S., Hauchecorne, A., Keckhut, P., McGee, T., Singh, U. N., and Gross, M. R.: Validation of temperature measurements from the halogen occultation experiment, J. Geophys. Res., 101(D6), 10277-10285, 1996.

Hervig, M. E., Gordley, L. L., Russell III, J. M., Bailey, S., and Baumgarten, G.: Interpretation of SOFIE PMC measurements: 
Cloud identification and derivation of mass density, particle shape, and particle size, J. Atmos. Solar-Terr. Phys., 71(3-4), 316-330, doi:10.1016/j.jastp.2008.07.009, 2009.

Kutepov, A. A., Feofilov, A. G., Marshall, B. T., Gordley, L. L., Pesnel, W. D., Goldberg, R. A., and Russell III, J. M.: SABER temperature observations in the summer polar mesosphere and lower thermosphere: importance of accounting for the $\mathrm{CO}_{2}$ 2 quanta V-V exchange, Geophys. Res. Lett., 33, L21809, doi:10.1029/2006GL026591, 2006.

Lopez-Puertas, M. and Taylor, F. W.: Non-LTE Radiative Transfer in the Atmosphere, World Scientific Publishing Co., Singapore, 2001.

Manney, G. L., Schwartz, M. J., Krüger, K., Santee, M. L., Pawson, S., Lee, J. N., Daffer, W. H., Fuller, R. A., and Livesey, N. J.: Aura microwave limb sounder observations of dynamics and transport during the record-breaking 2009 Arctic stratospheric major warming, Geophys. Res. Lett., 36, L12815, doi:10.1029/2009GL038586, 2009.

Marshall, B. T., Gordley, L. L., and Chu, D. A.: BANDPAK: Algorithms for modeling broadband transmission and radiance, J. Quant. Spectrosc. Ra., 52(5), 581-599, 1994.

McCormick, M. P., Zawodny, J. M., Veiga, R. E., Larsen, J. C., and Wang, P. H.: An overview of SAGE I and II ozone measurements, Planet. Space Sci., 37(12), 1567-1586, 1989.

Mertens, C. J., Mlynczak, M. G., Lopez-Puertas, M., Wintersteiner, P. P., Picard, R. H., Winick, J. R., Gordley, L. L., and Russell III, J. M.: Retrieval of mesospheric and lower thermospheric kinetic temperature from measurements of $\mathrm{CO}_{2} 15 \mu \mathrm{m}$ Earth limb emission under non-LTE conditions, Geophys. Res. Lett., 28(7), 1391-1394, doi:10.1029/2000GL012189, 2001.

Mill, J. D. and Drayson, S. R.: A nonlinear technique for inverting limb absorption profiles, in: Remote Sensing of the Atmosphere: Inversion Methods and Applications, edited by: Fymat, A. L. and Zeuev, V. E., Elsevier, New York, 123-135, 1978.

Niro, F., Jucks, K., and Hartmann, J.-M.: Spectra calculations in central and wing regions of $\mathrm{CO}_{2}$ IR bands. IV : Software and database for the computation of atmospheric spectra, J Quant Spectrosc Radiat Transfer, 95, 469-481, doi:10.1016/j.jqsrt.2004.11.011, 2005.

Remsberg, E. E., Marshall, B. T., Garcia-Comas, M., Krueger, D., Lingenfelser, G. S., Martin-Torres, J., Mlynczak, M. G., Russell III, J. M., Smith, A. K., Zhao, Y., Brown, C., Gordley, L. L., Lopez-Gonzalez, M. J., Lopez-Puertas, M., She, C. Y., Taylor, M. J., and Thompson, R. E.: Assessment of the quality of the retrieved temperature versus pressure profiles in the middle atmosphere from TIMED/SABER, J. Geophys. Res., 113, D17101, doi:10.1029/2008JD010013, 2008.

Rothman, L. S., Barbe, A., Benner, D. C., Brown, L. R., CamyPeyret, C., Carleer, M. R., Chance, K., Clerbaux, C., Dana, V., Devi, V. M., Fayt, A., Flaud, J.-M., Gamache, R. R., Goldman, A., Jacquemart, D., Jucks, K. W., Lafferty, W. J., Mandin, J.-Y., Massie, S. T., Nemtchinov, V., Newnham, D. A., Perrin, A., Rinsland, C. P., Schroeder, J., Smith, K. M., Smith, M. A. H., Tang, K., Toth, R. A., Vander Auwera, J., Varanasi, P., and Yoshino, K.: The HITRAN molecular spectroscopic database: edition of 2000 including updates through 2001, J. Quant. Spectrosc. Radiat. Transfer, 82, 5-44, doi:10.1016/S0022-4073(03)00146-8, 2003.

Russell III, J. M., Gordley, L. L., Park, J. H., Drayson, S. R., Hes- keth, W. D., Cicerone, R. J., Tuck, A. F., Frederick, J. E., Harries, J. E., and Crutzen, P. J.: The halogen occultation experiment, J. Geophys. Res., 98, 10777-10797, 1993.

Russell III, J. M., Mlynczak, M. G., Gordley, L. L., Tansock, J., and Esplin, R.: An overview of the SABER experiment and preliminary calibration results, Proc. SPIE, 3756, 277-288, 1999.

Schwartz, M. J., Lambert, A., Manney, G. L., Read, W. G., Livesey, N. J., Froidevaux, L., Ao, C. O., Bernath, P. F., Boone, C. D., Cofield, R. E., Daffer, W. H., Drouin, B. J., Fetzer, E. J., Fuller, R. A., Jarnot, R. F., Jiang, J. H., Jiang, Y. B., Knosp, B. W., Kruger, K., Li, J.-L. F., Mlynczak, M. G., Pawson, S., Russell III, J. M., Santee, M. L., Snyder, W. V., Stek, P. C., Thurstans, R. P., Tompkins, A. M., Wagner, P. A., Walker, K. A., Waters, J. W., and Wu, D. L.: Validation of the aura microwave limb sounder temperature and geopotential height measurements, J. Geophys. Res., 113, D15S11, doi:10.1029/2007JD008783, 2008.

Sica, R. J., Izawa, M. R. M., Walker, K. A., Boone, C., Petelina, S. V., Argall, P. S., Bernath, P., Burns, G. B., Catoire, V., Collins, R. L., Daffer, W. H., De Clercq, C., Fan, Z. Y., Firanski, B. J., French, W. J. R., Gerard, P., Gerding, M., Granville, J., Innis, J. L., Keckhut, P., Kerzenmacher, T., Klekociuk, A. R., Kyrö, E., Lambert, J. C., Llewellyn, E. J., Manney, G. L., McDermid, I. S., Mizutani, K., Murayama, Y., Piccolo, C., Raspollini, P., Ridolfi, M., Robert, C., Steinbrecht, W., Strawbridge, K. B., Strong, K., Stbi, R., and Thurairajah, B.: Validation of the Atmospheric Chemistry Experiment (ACE) version 2.2 temperature using ground-based and space-borne measurements, Atmos. Chem. Phys., 8, 35-62, doi:10.5194/acp-8-35-2008, 2008.

Ward, D. M. and Herman, B. M.: Refractive sounding by use of satellite solar occultation measurements including an assessment of its usefulness to the stratospheric aerosol and gas experiment program, Appl. Optics, 37, 8306-8317, 1998.

Waters, J. W., Read, W. G., Froidevaux, L., Jarnot, R. F., Cofield, R. E., Flower, D. A., Lau, G. K., Pickett, H. M., Santee, M. L., Wu, D. L., Boyles, M. A., Burke, J. R., Lay, R. R., Loo, M. S., Livesey, N. J., Lungu, T. A., Manney, G. L., Nakamura, L. L., Perun, V. S., Ridenoure, B. P., Shippony, Z., Siegel, P. H., Thurstans, R. P., Harwood, R. S., and Filipiak, M. J.: The UARS and EOS microwave limb sounder experiments, J. Atmos. Sci., 56, 194-218, 1999.

Wu, W.-S., Purser, R. J., and Parrish, D. F.: Three-Dimensional Variational Analysis with Spatially Inhomogeneous Covariances, Mon. Weather Rev., 130(12), 2905-2916, 2002. 